
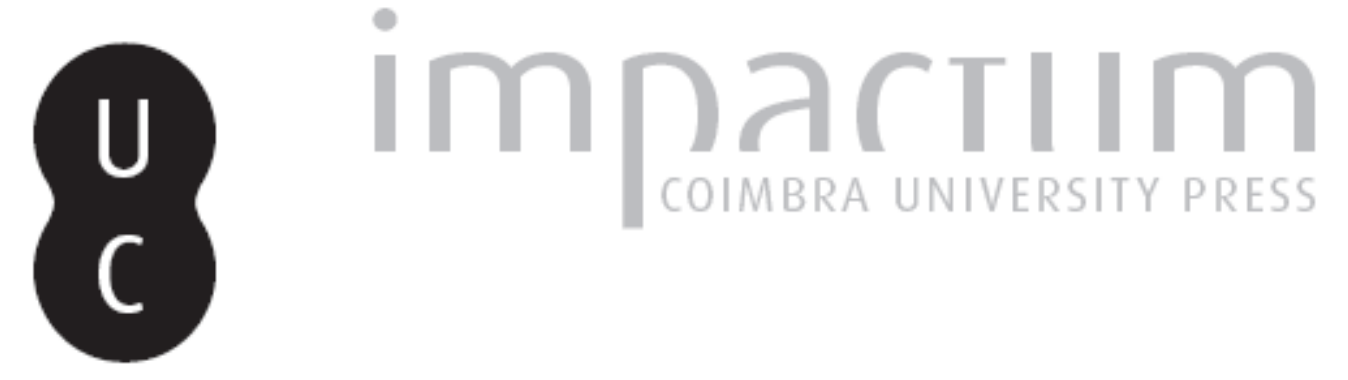

\title{
Novos dados sobre a ocupação romano-republicana do Algarve ocidental: cerâmica comum e outros objectos da Urbanização do Molião (Lagos, Portugal)
}

Autor(es): $\quad$ Sousa, Elisa de; Pereira, Teresa; Alves, Catarina

Publicado por: Faculdade de Letras da Universidade de Coimbra

URL

persistente:

URI:http://hdl.handle.net/10316.2/39127

DOI:

DOI:http://dx.doi.org/10.14195/1647-8657_54_4

Accessed : $\quad$ 26-Apr-2023 10:42:29

A navegação consulta e descarregamento dos títulos inseridos nas Bibliotecas Digitais UC Digitalis, UC Pombalina e UC Impactum, pressupõem a aceitação plena e sem reservas dos Termos e Condições de Uso destas Bibliotecas Digitais, disponíveis em https://digitalis.uc.pt/pt-pt/termos.

Conforme exposto nos referidos Termos e Condições de Uso, o descarregamento de títulos de acesso restrito requer uma licença válida de autorização devendo o utilizador aceder ao(s) documento(s) a partir de um endereço de IP da instituição detentora da supramencionada licença.

Ao utilizador é apenas permitido o descarregamento para uso pessoal, pelo que o emprego do(s) título(s) descarregado(s) para outro fim, designadamente comercial, carece de autorização do respetivo autor ou editor da obra.

Na medida em que todas as obras da UC Digitalis se encontram protegidas pelo Código do Direito de Autor e Direitos Conexos e demais legislação aplicável, toda a cópia, parcial ou total, deste documento, nos casos em que é legalmente admitida, deverá conter ou fazer-se acompanhar por este aviso.

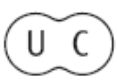


CONIMBRIGA

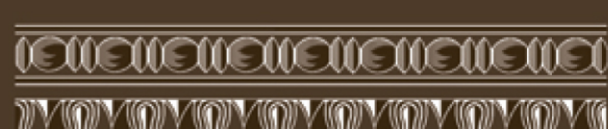

WN N N N

INSTITUTO DE ARQUEOLOGIA

VOLUME LIV • 2015

FACULDADE DE LETRAS 
ELISA DE Sousa

Uniarq - Centro de Arqueologia da Universidade de Lisboa/Fundação para a Ciência e a Tecnologia

e.sousa@campus.ul.pt

Teresa PEReira

Uniarq - Centro de Arqueologia da Universidade de Lisboa/Fundação para a Ciência e a Tecnologia

teresa.rita.pereira@gmail.com

Catarina Alves

Uniarq - Centro de Arqueologia da Universidade de Lisboa/Fundação para a Ciência e a Tecnologia

catarina4alves@gmail.com

NOVOS DADOS SOBRE A OCUPAÇÃO ROMANO-REPUBLICANA DO ALGARVE OCIDENTAL: CERÂMICA COMUM

E OUTROS OBJECTOS DA URBANIZAÇÃO DO MOLIÃO

(LAGOS, PORTUGAL)

NEW DATA CONCERNING THE ROMAN-REPUBLICAN

OCCUPATION OF WESTERN ALGARVE: COMMON WARE

AND OTHER OBJECTS FROM URBANIZAÇÃO DO MOLIÃO

(LAGOS, PORTUGAL)

“Conimbriga" LIV (2015) p. 81-131

http://dx.doi.org/10.14195/1647-8657_54_4

Resumo: Este trabalho centra-se na análise de um conjunto consideravelmente amplo de materiais recolhidos durante as escavações preventivas realizadas nas imediações da estação arqueológica de Monte Molião (Lagos, Portugal). Foca, em particular, as cerâmicas genericamente designadas de uso comum e alguns outros

Conimbriga, 54 (2015) 81-131 
objectos de cerâmica, pasta vítrea e líticos que foram recuperados em contextos datáveis do período romano-republicano (finais do século II / inícios do século I a.C.). Incorporam diversos tipos de produções, entre as quais se destacam as provenientes da Península Itálica, as de várias áreas regionais da antiga Iberia (Baía de Cádis, Guadalquivir e costa oriental) e ainda vários exemplares de origem local. O interesse deste estudo relaciona-se, sobretudo, com a associação contextual destes materiais com outros artefactos datantes (ânforas e cerâmica fina), o que permite uma caracterização detalhada do horizonte material da fase mais arcaica da ocupação romana do Algarve.

Palavras-chave: cerâmica comum; Algarve; Monte Molião; Romano-republicano

ABSTRACT: This work focuses on the analysis of a considerable wide range of artifacts collected during preventive excavations that took place in the surrounding area of Monte Molião's archaeological site (Lagos, Portugal). It is centered, in particular, in the study of common ware and some other ceramic, glass and lithic artifacts that were recovered in Roman Republican contexts (late 2nd/ early 1 st century $\mathrm{BC}$ ). It incorporates various types of productions, namely from the Italian peninsula, various regional areas of ancient Iberia (Cadiz bay, Guadalquivir and the East coast) and also several vases of local origin. The interest of this study relates mainly to its contextual association with other artifacts (amphorae and table ware), which allows a detailed characterization of the material culture of the most ancient Roman occupation phase in Algarve.

KEYwORDS: common ware; Algarve; Monte Molião; Roman-republican 


\section{NOVOS DADOS SOBRE A OCUPAÇÃO \\ ROMANO-REPUBLICANA DO ALGARVE OCIDENTAL: CERÂMICA COMUM E OUTROS OBJECTOS DA URBANIZAÇÃO DO MOLIÃO (LAGOS, PORTUGAL)}

\section{Introdução}

As intervenções arqueológicas realizadas pela empresa Palimpsesto - Estudo e Preservação do Património Cultural Lda., entre 2005 e 2006, na zona de protecção do sítio de Monte Molião (Lagos, Portugal) permitiram identificar um conjunto de estruturas negativas localizadas a Nordeste da área habitacional cuja funcionalidade, infelizmente, é ainda difícil de discernir. A sua construção foi, contudo, seguramente realizada durante a fase romano-republicana, atendendo à cronologia dos materiais associados aos seus primeiros níveis de enchimento, datáveis entre os finais do século II a.C. e os inícios da centúria seguinte (SOUSA e SERra 2006: 16).

Trata-se, mais concretamente, de dois interfaces negativos escavados no substrato geológico, separados por cerca de 12 m de distância, cujos enchimentos foram removidos em toda a sua extensão. A estrutura de maiores dimensões (cerca de $6 \mathrm{~m}$ de largura por $9 \mathrm{~m}$ de comprimento e com profundidade média de 1,40 m) apresenta uma forma sub-ovalada (U.E. [18]). No seu interior foram documentadas três camadas, sendo a mais recente (U.E. [7]) de cronologia alto-imperial, e as mais antigas (U.E. [14] e [35]) do período republicano, de onde é, aliás, proveniente a maioria dos materiais presentemente analisados. A outra estrutura negativa apresenta dimensões mais modestas (cerca de $4 \mathrm{~m}$ por $3 \mathrm{~m}$ e uma profundidade média de $0,60 \mathrm{~m}$ ) e um formato sub-circular. Os níveis escavados no seu interior (U.E.s [36], [37], [38], [39], [44], [46] e [47]) são, ao que tudo indica, coevos dos anteriores (finais do século II/inícios do século I a.C.).

Parte do conjunto artefactual recuperado nestes estratos roma- 
no-republicanos foi já analisado, concretamente os metais (PereIRA, Alves e Sousa 2015), as ânforas (Sousa, Alves, Pereira no prelo) e a cerâmica dita fina (Alves, Sousa, Pereira no prelo). Resta, agora, dar a conhecer a categoria mais expressiva deste conjunto, a cerâmica comum, apesar de este ser o elemento que maior dificuldade apresenta em termos de análise. Tal situação advém não só da grande expressividade quantitativa desta categoria cerâmica, que dificulta naturalmente a sua sistematização, mas também da escassez de estudos similares que permitam um melhor enquadramento cronológico, funcional e cultural destes materiais. No entanto, a recente publicação de conjuntos análogos recuperados na área do povoado de Monte Molião (Sousa e ARRUDA 2014a; Sousa e ARRUdA 2014b) permitem uma análise comparativa entre estas duas realidades que podem, com grande probabilidade, coincidir e corresponder a um mesmo episódio da fase de ocupação romana-republicana desta estação.

Aproveitamos ainda este trabalho para incluir outros artefactos relacionados com actividades mais específicas (cossoiros, pesos de tear, artefactos de pedra e de osso polido) e também alguns elementos de adorno que foram recuperados em associação aos restantes materiais, e cuja publicação isolada não nos pareceu pertinente.

\section{A cerâmica comum: limitações e potencialidades}

A análise de conjuntos da cerâmica de uso comum é uma das tarefas mais árduas do estudo da cultura material de qualquer período cronológico. Os principais factores dessa dificuldade relacionam-se por um lado, com a sua abundância e, por outro, na sua ampla variedade morfológica, que inclui, por vezes, uma multiplicidade de áreas de produção que frequentemente ultrapassam a escala local/regional. Estas limitações, associadas ao seu escasso potencial enquanto indicador cronológico são factores que têm justificado a remissão dos estudos específicos sobre este tipo de material para um plano secundário.

Paradoxalmente, e no que diz respeito especificamente ao período romano-republicano, a cerâmica comum constitui um dos melhores indicadores que reflete as profundas alterações culturais que advêm da integração do território actualmente português na esfera da conquista romana. A adopção de novas técnicas, hábitos alimentares e culinários é um elemento crucial para compreender os ritmos de romanização das 
comunidades peninsulares e que é observável, para além do serviço de mesa, em alterações verificadas na cerâmica destinada à confecção de alimentos. Por outro lado, o início da conquista romana dos territórios mais ocidentais comportou toda uma nova dinâmica em termos de movimentações de populações e de contactos inter-regionais que também deixou marcas profundas na cultura material quotidiana das zonas envolvidas e que pode, uma vez mais, transparecer nas especificidades da cerâmica de uso comum.

Análises detalhadas sobre a totalidade de conjuntos de cerâmica comum, quando conjugadas com dados estratigráficos que permitam delinear fases de ocupação específicas de sítios arqueológicos, podem ainda permitir estabelecer cronologias mais precisas para determinados tipos de formas, que podem ser valiosas quando extrapoladas para outras estações com menor poder aquisitivo, que se reflete, naturalmente, na escassez de cerâmicas finas, de contentores anfóricos e outros tipos de materiais datantes. Como tal, consideramos ser plenamente justificada a publicação do conjunto que aqui apresentamos.

Neste âmbito, é importante ainda referir que, durante os últimos anos, os estudos de conjuntos de cerâmica comum da fase final da Idade do Ferro e do período romano-republicano têm sido progressivamente valorizados, em particular nas áreas mais meridionais da Andaluzia, situação que nos permite estabelecer paralelos directos com o conjunto aqui apresentado. Os estudos realizados na área da Baía de Cádis (SÁEz Romero 2005; 2008; 2014) e no Guadalquivir (Ferrer Albelda e García Fernández 2008; García Vargas e García Fernandez 2009; García FernandeZ e García Vargas 2010; García FernandeZ 2014) têm vindo a sistematizar a evolução dos repertórios de cerâmica comum de âmbito gaditano e "turdetano", permitindo compreender o peso que as tradições indígenas e as influências exógenas exerceram na dieta alimentar e práticas culinárias dessas comunidades durante os séculos III e II a. C.

\section{A cerâmica comum romano-republicana da Urbanização do Molião}

O estudo da cerâmica comum recuperada nos níveis romano-republicanos identificados na Urbanização do Moleão segue os mesmos parâmetros metodológicos utilizados na publicação do conjunto análogo 
recolhido na área do habitat (SousA e ARRUDA 2014b: 56-57): inclui todos os exemplares provenientes dos estratos datáveis entre finais do século II e inícios do séc. I a. C., integrando produções manuais e a torno, independentemente da aplicação de motivos decorativos, sendo quantificadas de acordo com o método do Número Mínimo de Indivíduos - NMI (ARCELIN e TufFreAU-Libre 1998). Os materiais foram separados de acordo com as suas características de fabrico e posteriormente classificados por categorias morfo-funcionais.

O conjunto de cerâmica comum engloba 1767 fragmentos de bordo, asa, parede e fundo, que se traduzem em 1278 NMI.

Foram individualizadas sete áreas de produção diferenciadas, concretamente a Baía de Cádis (1177 fragmentos - 844 NMI), duas áreas presumivelmente localizadas no Baixo Guadalquivir (Guadalquivir A - 15 fragmentos - 12 NMI; Guadalquivir B - 78 fragmentos - 60 NMI), a fachada oriental da Península Ibérica (24 fragmentos $23 \mathrm{NMI}$ ), produções itálicas (136 fragmentos - $105 \mathrm{NMI}$ ), produções locais a torno (276 fragmentos - $196 \mathrm{NMI})$ e produções manuais $(60$ fragmentos - 37 NMI). Um único exemplar (1 fragmento - 1 NMI) não permitiu nem a adscrição de uma área de proveniência específica, nem um enquadramento tipológico.

\subsection{Produções gaditanas}

As produções da Baía de Cádis constituem o grupo mais bem representado no conjunto da cerâmica comum recolhido nos níveis de cronologia romano-republicana da Urbanização do Moleão. Engloba 1177 fragmentos (844 NMI), que correspondem a 66,04\%.

Este fabrico caracteriza-se por englobar pastas porosas e arenosas, de textura fina e mediamente depuradas, com tonalidades que oscilam entre o castanho amarelado e o bege rosado.

As formas abertas dominam no conjunto destas produções, particularmente os recipientes classificados como tigelas. Trata-se de uma categoria provavelmente multi-funcional, podendo ter sido utilizada em diversas etapas da preparação, confecção e consumo de alimentos. A possibilidade de serem usadas como tampas de outros recipientes deve ser também considerada (SÁEz Romero 2005: 150; 2008: 625). Neste grupo, o tipo mais bem representado (463 NMI) é a tigela de perfil semi-hemisférico, de bordo simples e secção arredondada, por vezes 
engrossado, da forma GDR 1.2.1, de acordo com a tipologia proposta por A. Sáez Romero (2005: 149-150). Outras variantes semelhantes à anterior, concretamente o tipo GDR 1.2.2 (60 NMI), com o bordo apontado, e o tipo GDR 1.2.3 (8 NMI), com paredes rectas, são consideravelmente mais raras.

Taças de pequena dimensão, de perfil tendencialmente semi-hemisférico e bordo reentrante, integráveis nos tipos GDR 1.1.1 (3 NMI) e 1.1.2 (28 NMI), foram também documentadas no conjunto. Este tipo de recipientes seria primariamente utilizado no serviço de mesa para conter condimentos ou molhos (Sousa 2009: 78). No entanto, a sua utilização enquanto cerâmica de iluminação está documentada no Sul do território peninsular (SÁEz Romero 2005: 149; 2008: 624; MAIA 2007; Sousa 2009: 78). Nesta mesma categoria morfo-funcional, deve incluir-se um outro exemplar (1 NMI - n. $\left.{ }^{\circ} 70\right)$, ainda que de maiores dimensões, exibindo um bordo exvertido e de secção sub-triangular, e que não é integrável em nenhuma das variantes até ao momento estabelecidas para as produções gaditanas. A sua utilização estaria, provavelmente, relacionada com o serviço de mesa.

Recipientes abertos de dimensões manifestamente mais amplas e de perfil carenado, enquadráveis no tipo GDR 2.1.1 (SÁEZ Romero 2005: 149; 2008: 626) são raros no conjunto, contando com um único exemplar (1 NMI - n. $\left.{ }^{\circ} 75\right)$. A sua função estaria, provavelmente, ligada à preparação e confecção de alimentos, não sendo ainda de excluir a possibilidade de terem sido utilizadas como tampas (SÁEz RoMERo 2005: 151; 2008: 626, 630).

No conjunto de cerâmica comum republicana recolhido na Urbanização do Moleão identificaram-se também quatro fragmentos de almofarizes (2 NMI), utilizados na preparação de alimentos (triturar, moer, misturar). Um integra-se na variante GDR 3.1.2 (SÁEz Romero 2008: 629), correspondendo a um fragmento de bordo de secção sub-triangular (n. $\left.{ }^{\circ} 38\right)$, sendo os restantes fundos anelares que exibem, na superfície interna, incrustações de elementos não plásticos que seguramente facilitariam o atrito, sendo apenas genericamente integráveis na série GDR 3.1.

Recipientes mais amplos, de tipo bacia e/ou alguidar estão relativamente bem representados, englobando vasos de perfil tendencialmente hemisférico (4 NMI - n. $\left.{ }^{\circ} 1934,1869\right)$ e carenado (5 NMI - n. ${ }^{\circ}$ 2874, 57), correspondendo às variantes GDR 4.1.1 ou 4.4.1/2/3 (SÁEz Romero 2005: 154-155; 2008: 632-636). Trata-se de recipientes 
destinados à preparação e confecção de alimentos (NiveAU DE VILLEDARY Y MARIÑAS 2003: 14), inclusivamente de vinho (NiveAu DE VILLEDARY Y MARIÑAS 2009: 131), não sendo se excluir a sua utilização no armazenamento e em tarefas de higiene pessoal (SousA 2009: 83).

Os pratos, que consistem numa das forma mais expressivas deste conjunto, integram exclusivamente os chamados "pratos de peixe" (59 fragmentos - $51 \mathrm{NMI}$ ), apresentando o típico bordo pendente e a depressão central na área interna do fundo. Correspondem ao tipo GDR 5.1.1/2 (SÁEz Romero 2005: 155-156; 2008: 638) e são utilizados principalmente no serviço de mesa.

Outros fragmentos exibem características morfológicas que permitem a sua inclusão no grupo das tampas, sendo divisíveis em duas variantes, a primeira de bordo simples e de secção arredondada (6 NMI $-\mathrm{n}$. $\left.^{\circ} 2392,1864\right)$, e a segunda, mais frequente, de bordo aplanado (11 NMI - 1877, 1293). Equivalem ao tipo GDR 6 (SÁez Romero 2005: 156-157; 2008: 638-639).

As formas fechadas são menos abundantes no conjunto, sendo o tipo mais bem representado os recipientes englobáveis na categoria morfo-funcional genericamente designada de pote e/ou panela. No caso das produções gaditanas, a utilização destes vasos estaria provavelmente, mais ligada à armazenagem do que à confecção de alimentos, considerando que as características do seu fabrico dificultariam uma exposição permanente ao fogo (PINTo 2004: 13). Estes recipientes manifestam uma considerável variabilidade em termos morfológicos, que, por vezes, não permite uma integração directa nos quadros tipológicos estabelecidos. Todas as formas encontram, contudo, paralelos no conjunto de cerâmica comum romano-republicana proveniente da área de habitat de Monte Molião (Sousa e Arruda 2014a; 2014b).

Uma das variantes deste conjunto de potes e/ou panelas caracteriza-se por exibir um bordo simples, de tendência ligeiramente exvertida, sendo, contudo, bastante rara no conjunto, contando com um único exemplar (1 NMI - n. $\left.{ }^{\circ} 2149\right)$.

Outros vasos (3 NMI - n. $\left.{ }^{\circ} 2252,61\right)$, apesar de semelhantes ao anteriormente descrito, distinguem-se por apresentarem um bordo mais exvertido e espessado.

Um outro exemplar (1 NMI $-\mathrm{n} .^{\circ}$ 3146) exibe um bordo simples, aplanado e ligeiramente engrossado, com uma pequena ranhura na sua zona superior.

Também raros no conjunto presentemente estudado (1 NMI - 
n. ${ }^{\circ}$ 768) são os vasos de bordo exvertido, de secção arredondada e de paredes mais rectilíneas.

Mais bem representados em termos quantitativos (11 NMI n. ${ }^{\circ} 2648,77,2241$ ) estão os potes piriformes de bordo triangular, enquadráveis no tipo GDR 8 (SÁEZ RoMERo 2005: 158-159; 2008: 641-644).

Entre as diversas morfologias de potes e/ou panelas de produção gaditana, uma das formas mais expressivas (45 NMI) corresponde a vasos de colo largo e curto, de bordo bem assinalado externamente, que pode exibir uma secção sub-arredondada ou triangular (n. ${ }^{\circ} 2641,1900$, $65,2634,1124,74,69,2488,2906,72,2823)$.

Uma outra variante (40 NMI), semelhante à anterior mas distinguível por apresentar um colo consideravelmente mais alto e rectilíneo, e com bordos pendentes de secção sub-arredondada ou triangular (n. $\left.{ }^{\circ} 2029,2054,2085,67,2768,2370,2373,63\right)$, é também numerosa, aproximando-se das variantes GDR 12.1 ou 12.2 (SÁEz RoMERo 2005: 165; 2008: 654).

Por último, deve ainda destacar-se a presença de dois exemplares (2 NMI) com bordos reentrantes e aplanados, que formam um pequeno sulco interno $\left(\mathrm{n} .^{\circ} 2461,194\right)$.

No grupo das formas fechadas de produção gaditana identificam-se ainda quatro fragmentos $\left(4 \mathrm{NMI}-\mathrm{n} .^{\circ} 2764,71,1185,1871\right)$ de vasos com colo alto e estreito e bordos simples de menor diâmetro, que parecem correspondem às pequenas jarras do tipo GDR 10 (SÁEZ ROMERo 2005: 159-162; 2008: 645-648), utilizadas para o serviço de líquidos, presumivelmente vinho (NIVEAU DE VILlEDARY y MariÑaS 2009: 141).

Dois outros fragmentos (2 NMI - 2647, 2680) são difíceis de integrar nos quadros tipológicos conhecidos, podendo, provavelmente, corresponder a vasos de pequena dimensão de possível uso sumptuário.

No grupo das produções gaditanas constam ainda 89 fragmentos de bordo (89 NMI) que, dado o seu elevado estado de fragmentação, não permitiram uma classificação tipológica específica.

Os fragmentos de fundo são abundantes, sendo divisíveis em várias morfologias. Os mais frequentes apresentam uma base plana ou convexa, com um pé destacado (181 fragmentos - n. ${ }^{\circ} 2369,182$, $2758,2346,3014,2334,2078,2069,2804,116,2622,2599,115)$ que, muito provavelmente, correspondem à parte inferior das tigelas do tipo GDR 1.2 (SÁEz Romero 2005: 149-150). Deve ainda referir-se que um destes fragmentos apresenta uma incisão em forma de $\mathrm{X}$ na zona 
externa, provavelmente uma marca de propriedade, sendo um elemento frequente no Sul peninsular (NIVEAU DE VILLEDARY y MARIÑAS 2004: 136-137; SÁEZ RoMero 2008: 428). Outros exemplares apresentam um pé anelar ( 25 fragmentos $\left.-n .^{\circ} 2079,2337,2627,2380\right)$, uma base simples plana (18 fragmentos $-\mathrm{n} .^{\circ} 2748$ ) ou convexa (15 fragmentos n. ${ }^{\circ}$ 117) e, com menor frequência, um fundo em ônfalo (4 fragmentos).

As asas integráveis nesta produção apresentam sobretudo secções ovais (21 fragmentos) e circulares (31 fragmentos), contando-se apenas alguns escassos exemplares com asas de fita (4 fragmentos) e apenas uma asa cega.

Inventariaram-se ainda dois exemplares que parecem correspondem a algum tipo de bico ou de gargalo e 21 fragmentos de parede com bandas de tonalidades avermelhadas, violáceas e acastanhadas na superfície externa, característica decorativa que, apesar de rara, não é completamente desconhecida no âmbito das produções gaditanas (SÁEz RoMERo 2008: 619-622; 2014: 37; NiveAU DE ViLLEDARY y MariÑas 2009: 127).

\subsection{Produções do Guadalquivir A}

Vasos de cerâmica comum produzidos nesta área do Guadalquivir são pouco expressivos, incorporando apenas 15 fragmentos (15 NMI), que traduzem somente $0,94 \%$ do conjunto.

As pastas deste fabrico apresentam muitas semelhanças com as dos contentores anfóricos que serão produzidos, na mesma área, dentro de poucas décadas, como por exemplo os tipos Haltern 70 ou Dressel 20 (Sousa e ARruda 2014b: 68), o que justifica a adscrição deste grupo a esta área geográfica. Correspondem a pastas mal depuradas, com elementos não plásticos de formato sub-arredondado, e cujas tonalidades variam entre o bege esbranquiçado e o amarelo-claro.

As formas identificadas neste grupo resumem-se apenas a duas.

A primeira engloba bacias e/ou alguidares, que podem exibir um de perfil carenado (7 NMI - n. $\left.^{\circ} 2601\right)$ ou paredes mais oblíquas (1 NMI - n. $\left.^{\circ} 3020\right)$.

O segundo tipo corresponde a recipientes de grande dimensão, de tipo dolia (3 NMI - n. ${ }^{\circ} 59,66,73$ ), de bordo exvertido e engrossado, e colo curto.

Ambas as formas encontram-se bem documentadas na área do habitat de Monte Molião (Sousa e ArRuda 2014b: 68-70).

Conimbriga, 54 (2015) 81-131 
Um único fragmento de bordo (1 NMI) não permitiu uma classificação tipológica mais precisa.

Nesta produção identificaram-se ainda dois fundos planos de dimensões consideráveis e uma asa de secção oval.

\subsection{Produções do Guadalquivir B}

Um outro fabrico cuja origem poderá ser geograficamente próxima à das produções anteriormente descritas foi também identificado entre a cerâmica comum romana-republicana da Urbanização do Moleão, englobando 78 fragmentos (60 NMI) que correspondem a 4,69\% do conjunto.

Estas produções caracterizam-se por apresentarem pastas compactas e pouco depuradas, com elementos não plásticos de média dimensão de formato sobretudo sub-arredondado e, mais raramente, sub-angulosos. As suas tonalidades variam entre o amarelo claro e o amarelo alaranjado. Com alguma frequência, detectam-se vestígios da aplicação de bandas pintadas nas superfícies destes vasos, geralmente de coloração avermelhada ou violácea.

A frequência destas características decorativas na área "turdetana" do vale do Guadalquivir (Ferrer Albelda e García Fernández 2008; García Vargas e García Fernandez 2009; García Fernandez e García VARgas 2010; García Fernandez 2014) é um dos elementos que suporta a adscrição deste grupo a esta área geográfica, apesar de não se poder ainda excluir, de forma taxativa, outras procedências, como por exemplo as zonas interiores da Campiña de Cádis.

Este conjunto apresenta uma considerável variedade formal.

No grupo das formas abertas, identificaram-se vários fragmentos de tigelas de perfil semi-hemisférico (10 NMI - $\left.\mathrm{n}^{\circ}{ }^{\circ} 1855\right)$, formalmente idênticas às das produções gaditanas do tipo GDR 1.2.1 (FERRER Albelda e García Fernández 2008: 208; García Vargas e García Fernandez 2009: 148; García Fernandez e García Vargas 2010: 126-127).

Uma pequena taça de perfil semi-hemisférico e de bordo reentrante (1 NMI $-\mathrm{n}^{\circ}{ }^{\circ}$ 2203), semelhante ao tipo GDR 1.1.2 (FERRER Albelda e García Fernández 2008: 208; García Vargas e García FERNANDEZ 2009: 149), foi também identificada no conjunto. Um outro exemplar enquadrável no grupo morfo-funcional das taças, mas com 
maior dimensão e um bordo aplanado e bem assinalado na área interna (1 NMI - n. . 2825), faz também parte dos materiais integráveis nesta produção, não tendo sido, contudo, possível identificar um paralelo específico para este tipo.

Entre as formas abertas, a morfologia mais bem representada corresponde aos vasos de tipo bacia e/ou alguidar. À semelhança do que ocorreu nas produções anteriores, foi possível distinguir duas variantes. A primeira, maioritária, engloba recipientes de perfil carenado (11 NMI - n. $\left.{ }^{\circ} 2742,918,3068,2274,2253\right)$, enquanto que a segunda (1 NMI $-\mathrm{n} .^{\circ}$ 919) se caracteriza pelo seu perfil tendencialmente semi-hemisférico. Ambas encontram-se bem documentadas nas áreas interiores do Guadalquivir (Ferrer Albelda e García Fernández 2008: 208-211; García Vargas e García Fernandez 2009: 141, 145; García FernandeZ e García VARGas 2010: 123-124).

Um único fragmento de tampa foi registado neste conjunto (1 NMI - n. ${ }^{\circ}$ 2956), exibindo um bordo aplanado e ligeiramente engrossado.

As formas fechadas são dominadas pelos potes e/ou panelas, tendo sido possível distinguir algumas variantes, quase todas detectáveis também no conjunto de cerâmica comum proveniente das escavações na área de habitat do Monte Molião (SousA e ArRudA 2014b: 72-74), estando também bem documentadas nas zonas interiores do vale do Guadalquivir (Ferrer Albelda e García Fernández 2008; García Vargas e García Fernandez 2009; García Fernandez e García VARGAS 2010).

A primeira engloba vasos de bordo simples, de seç̧ão arredondada, e ligeiramente exvertido (3 NMI - n. $\left.{ }^{\circ} 1147,2533\right)$.

Uma segunda variante inclui recipientes de bordo claramente exvertido, aplanado e engrossado, apresentando um colo curto (3 NMI - n. $\left.{ }^{\circ} 2247,2747\right)$. Um destes exemplares exibe uma banda de tonalidade vermelha-violácea sobre o bordo.

Um terceiro grupo, mais abundante (14 NMI - n. ${ }^{\circ} 2535,2745$, $1858,2596)$, incorpora vasos de bordo pendente, de secção geralmente triangular, e colo alto e de tendência vertical. Um destes exemplares exibe uma banda vermelha na zona superior externa.

Um outro fragmento (1 NMI - n. $\left.{ }^{\circ} 2774\right)$ apresenta um bordo exvertido, engrossado e aplanado, de secção sub-triangular, com colo curto e paredes oblíquas.

Por último, cinco exemplares (5 NMI - n. $\left.{ }^{\circ} 2209,2744,2462\right)$ exibem bordos exvertidos e pendentes, de secção sub-arredondada, 
apresentando uma pequena ranhura na área superior interna, provavelmente destinada a suportar uma tampa. A peça parece desenvolver um colo alto, rectilíneo e de tendência oblíqua. Trata-se da única forma que não encontra uma equivalência nos materiais de idêntica produção recuperados durante os trabalhos arqueológicos realizados na zona de habitat do Monte Molião (SousA e Arruda 2014a; 2014b). Apesar da semelhança formal com algumas formas identificadas na área do Guadalquivir (Ferrer Albelda e García Fernández 2008; García VArgas e García Fernandez 2009; García Fernandez e García VARGAS 2010), a presença da ranhura no bordo torna difícil o estabelecimento de paralelos exactos. Estas peças são, contudo, semelhantes a alguns exemplares de produção gaditana recolhidos no habitat de Monte Molião (SousA e Arruda 2014b: 62 - n. ${ }^{\circ} 12133$ e 11403), distinguindo-se apenas por apresentar um bordo mais pendente.

No conjunto dos materiais desta produção constam ainda nove fragmentos de bordo (9 NMI) que não permitiram uma integração tipológica específica.

Resta referir a recolha vários fragmentos de fundo que exibem, sobretudo, perfis planos ou convexos de pé destacado (4 fragmentos - n. $\left.{ }^{\circ} 2256,1906\right)$, anelares ( 5 fragmentos - n. $\left.{ }^{\circ} 2566\right)$, bases planas ( 3 fragmentos) e em ônfalo (1 fragmento).

Os fragmentos de asas são escassos, tendo sido identificados apenas dois exemplares, um deles de secção oval e o outro uma asa cega (n. $\left.{ }^{\circ} 2700\right)$.

Um outro fragmento (n. ${ }^{\circ}$ 2000) parece corresponder a um bico ou vertedor lateral de um grande recipiente, possivelmente de um alguidar.

Inventariam-se ainda dois fragmentos de paredes decorados com bandas violáceas na superfície externa (n. ${ }^{\circ}$ 2368), característica recorrente nas produções no interior do vale do Guadalquivir (FERRER Albelda e García Fernández 2008; García Vargas e García FERnANDEZ 2009; García FERnANDEZ e García VARgas 2010).

\subsection{Produções da costa oriental da Península Ibérica}

No conjunto de cerâmica comum exumado nos níveis romano-republicanos da Urbanização do Moleão identificou-se uma série de vasos (24 fragmentos - $23 \mathrm{NMI}$ ) cujas características de fabrico 
e morfologia indicam uma zona de proveniência da costa oriental da Península Ibérica. Corresponde a 1,80\% do conjunto.

Este fabrico apresenta pastas compactas e muito bem depuradas, cujas tonalidades variam entre o bege e o laranja claro.

Todos os exemplares deste grupo correspondem a uma única forma, o kalathos. Trata-se de recipientes de corpo cilíndrico e fundo convexo, sendo o bordo aplanado e tendencialmente horizontal, formando com frequência uma reentrância interna.

Um estudo recente destes materiais (MucCioli 2014) permitiu a sua classificação nos grupos A e B de Conde Berdós (1991), fabricados na área da Catalunha. A comercialização destes recipientes no território peninsular e mesmo no Mediterrâneo Central é uma realidade já bem documentada, apesar de não ser ainda claro se a sua difusão se relaciona primariamente com questões culturais, migratórias ou com a difusão de produtos alimentares específicos como, por exemplo, mel, frutas secas ou mesmo algum tipo particular de preparados piscícolas (CONDE BERDós 1991; 1998; MuCCIOLI 2014; MusColino 2006; TARRADEL e SANMARTí 1980).

\subsection{Produções itálicas}

A cerâmica comum produzida na Península Itálica é consideravelmente abundante entre os materiais recolhidos na Urbanização do Moleão, integrando 136 fragmentos (105 NMI), que constituem 8,22\% do conjunto.

Engloba pastas compactas e pouco depuradas, sendo possível identificar as características areias negras vulcânicas. As suas tonalidades variam entre o laranja e o avermelhado. Com frequência, a área exterior destes recipientes apresenta uma coloração escura, decorrente da sua utilização primária enquanto cerâmica de cozinha.

Em termos tipológicos, o conjunto da cerâmica comum itálica da Urbanização do Moleão é dominado pelas patinae (90 fragmentos). Trata-se de pratos de bordo bífido e paredes altas e geralmente arqueadas que terminam num fundo plano. Eram utilizados em tarefas de preparação e, sobretudo, confecção de alimentos (cozinhar e fritar) podendo posteriormente ser usados para servir. Dentro deste grupo, as patinae do tipo COM-IT 6c (BATS 1993) são as mais bem representadas (55 NMI). Outras variantes, como é o caso das patinae do tipo COM-IT 
6d (1 NMI) e COM-IT 6b (9 NMI) são consideravelmente mais raras.

As tampas são também uma presença frequente neste conjunto (43 fragmentos - $40 \mathrm{NMI}$ ), enquadrando-se no tipo COM-IT 7a (BATS, 1993), estando a sua utilização directamente associada ao tipo anterior.

Neste grupo, apenas três fragmentos de bordo (3 NMI) não permitiram uma classificação tipológica específica.

Trata-se de um conjunto característico no âmbito das ocupações de finais do século II / inícios do século I a.C. no Sul peninsular, como se verifica, por exemplo, na zona do Guadalquivir (GARCÍA VARGAS e García Fernandez 2009; García Fernandez e García Vargas 2010) e em Valência (Ribera I LACOMBA e MARÍN JoRDÁ 2003; Ribera I LACOMBA 2010), ainda que, nestes casos, se verifique uma maior diversidade formal. No entanto, cabe registar que essa variedade se verifica em contextos coevos escavados na área do habitat de Monte Molião (Sousa e ArRuda 2014a; 2014b).

\subsection{Produções locais/regionais a torno}

As produções locais/regionais feitas a torno são significativas no conjunto presentemente estudado, totalizando 276 fragmentos (196 NMI), que correspondem a $15,34 \%$.

Apresentam pastas não calcárias, mediamente compactas e mal depuradas, com elementos não plásticos sub-arredondados de pequena, média e, ocasionalmente, de grande dimensão. As suas tonalidades variam entre o alaranjado e o avermelhado. Trata-se, muito provavelmente, de produções elaboradas no próprio sítio arqueológico de Monte Molião.

No conjunto das formas abertas, identificaram-se vários exemplares de tigelas de perfil semi-hemisférico que equivalem, morfologicamente, aos tipos GDR 1.2.1 (24 NMI) e GDR 1.2.2 (2 NMI) já descritos para as produções gaditanas. Infelizmente, estes exemplares encontram-se muito fragmentados, não tendo sido possível a sua representação gráfica. Três outras peças, que podem ser incluídas também nesta categoria morfo-funcional, apresentam características mais singulares que possibilitam a sua individualização. Uma delas (1 NMI - n. ${ }^{\circ}$ 2969) exibe um bordo exvertido, formando um pequeno lábio na área interna. As restantes (2 NMI - n. $\left.{ }^{\circ} 1115\right)$ apresentam uma 
pequena reentrância na área superior interna, provavelmente destinada a suportar uma tampa.

Taças de pequena dimensão e de bordo reentrante assimiláveis ao tipo GDR 1.1.2 surgem também neste conjunto (2 NMI) sendo, contudo, consideravelmente mais grosseiras quando comparadas com os exemplares gaditanos.

As produções locais/regionais a torno incluem ainda recipientes de grandes dimensões de tipo bacia e/ou alguidar que exibem morfologias semelhantes às detectadas nas produções anteriormente descritas, concretamente com perfis carenados (7 NMI - n. ${ }^{\circ} 2618,149$, 96) e, mais raramente, hemisféricos (1 NMI - n. $\left.{ }^{\circ} 2971\right)$. Outros dois exemplares $\left(2 \mathrm{NMI}-\mathrm{n} .^{\circ} 3059,99\right)$ integráveis nesta categoria morfo-funcional encontram-se muito fragmentados, pelo que não é possível descrever as suas características morfológicas ao nível do perfil geral da peça. No entanto, o facto de apresentarem bordos claramente exvertidos, formando lábios pendentes, permitem a sua individualização face aos restantes.

As tampas estão escassamente representadas neste conjunto, contando com apenas quatro exemplares (4 NMI - n. $\left.{ }^{\circ} 152\right)$, apresentando perfis simples e um bordo ligeiramente aplanado.

As formas fechadas são as mais bem representadas no grupo das produções locais/regionais a torno, particularmente os vasos de tipo pote e/ou panela. Quase todas as variantes desta categoria morfo-funcional surgem no repertório artefactual da área de habitat de Monte Molião.

Uma primeira variante (1 NMI - n. $\left.{ }^{\circ} 2708\right)$, de menor dimensão, exibe um bordo simples, de secção arredondada e de tendência exvertida. Mais frequentes (59 NMI) são os recipientes de colo curto e com bordos mais exvertidos e geralmente engrossados, podendo chegar a formar um pequeno lábio pendente. As suas secções são consideravelmente diversificadas, podendo exibir um perfil sub-triangular (n. $\left.{ }^{\circ} 3825,2898,3072,2824,2632,2323,2301,2307,2978\right)$ ou mais arredondado (n. ${ }^{\circ} 2567,2610,150,2035,1968,850,1953,98,2988$, $1958,2329)$. Estes vasos, frequentes também na área do habitat de Monte Molião, apresentam algumas semelhanças morfológicas com o tipo 1 de Mercedes Vegas (1973) / COM-IT 1a (BATS, 1993), podendo tratar-se de uma morfologia directamente inspirada em formas itálicas (SouSA e ARRUDA 2014b, p. 81). Uma variante semelhante à anterior, distinguível apenas pela presença de um colo um pouco mais desen- 
volvido, é também significativa no conjunto ( $25 \mathrm{NMI}-\mathrm{n} .^{\circ} 2739,2331$, $151,2295,97,95)$. Um outro tipo de potes/panelas é caracterizado por recipientes de colo curto e estrangulado, com bordos de tendência exvertida e secções arredondadas que apresentam, na zona interna, uma reentrância destinada a suportar uma tampa (17 NMI - n. ${ }^{\circ}$ 3069, 1651, 3057, 979, 3098), aproximando-se, morfologicamente, dos vasos do tipo 2 de Mercedes Vegas/ COM-IT 1b (Sousa e Arruda 2014b: 81).

Dois outros exemplares exibem ainda características distintas dos anteriores, sendo também os únicos que não encontram paralelo no elenco morfológico identificado na área do povoado (SousA e ARRUDA 2014a; 2014b). Um deles (1 NMI - n. ${ }^{\circ}$ 2987) exibe características morfológicas idênticas às do tipo GDR 8.1.1 (SÁEz Romero 2005), podendo corresponder a uma imitação desta forma gaditana. O outro (1 NMI - n. $\left.{ }^{\circ} 100\right)$ parece corresponder a um vaso de colo alto e oblíquo, de bordo exvertido, formando um lábio pendente, de secção arredondada, sendo semelhante, em termos morfológicos, a alguns vasos produzidos na zona do Baixo Guadalquivir (Guadalquivir B), anteriormente caracterizados.

No conjunto das formas fechadas, deve ainda destacar-se a presença de recipientes de grande dimensão, de tipo dolia, provavelmente destinados ao armazenamento. Um dos exemplares (1 NMI $-\mathrm{n}^{\circ}{ }^{\circ}$ 2296) apresenta um colo alto e bordo exvertido de secção arredondada. Outros dois (2 NMI - n. ${ }^{\circ} 2037$ ) exibem bordos de secção sub-triangular e colos muito curtos, a partir do qual se desenvolve uma parede de tendência mais horizontal na parte superior.

Outros fragmentos de bordo (45 NMI) não permitiram uma classificação tipológica precisa devido ao seu deteriorado estado de conservação.

Neste conjunto, deve, por último, referir-se a recolha de vários fragmentos de asas de secção oval (12 fragmentos) e circular (9 fragmentos), uma asa cega e três fragmentos de parede que conservavam vestígios de pintura vermelha-violácea na superfície externa. Entre os fundos, identificaram-se perfis planos e convexos com pé destacado (18 fragmentos $\left.-\mathrm{n} .^{\circ} 197\right)$, anelares (22 fragmentos $\left.-\mathrm{n}^{\circ}{ }^{\circ} 2569,2729,198\right)$, bases planas (14 fragmentos $-\mathrm{n}^{\circ}{ }^{\circ} 2974$ ) e em ônfalo (1 fragmento). 


\subsection{Produções locais/regionais manuais}

No conjunto de cerâmica comum romano-republicana recolhido na Urbanização do Moleão identificaram-se ainda 60 fragmentos de produção manual (37 NMI), que correspondem a $2,90 \%$, muito provavelmente produzidos no próprio sítio.

Neste grupo, as formas abertas são raras, integrando uma taça de bordo ligeiramente reentrante (1 NMI $\left.-\mathrm{n}^{\circ}{ }^{\circ} 1154\right)$.

Um outro fragmento identificado neste conjunto parece corresponder a uma tampa (1 NMI) de bordo simples, ligeiramente aplanado, e de secção arredondada. Infelizmente, o seu estado de conservação não permitiu a sua representação gráfica.

A forma mais bem representada corresponde a recipientes de tipo pote e/ou panela, que são divisíveis em duas variantes. A primeira, mais abundante, integra vasos com perfil em $\mathrm{S}$, de bordo exvertido e de secção arredondada (23 NMI - n. ${ }^{\circ}$ 1650). A segunda variante exibe bordos simples, de tendência vertical, a partir do qual se desenvolve um corpo ovalado (10 NMI - n. $\left.{ }^{\circ} 1710,2303,856\right)$. Ambos os tipos encontram-se bem documentados na área de habitat do Monte Molião (SousA e ARRUDA 2014b: 83).

Dois outros fragmentos de bordo (2 NMI) não permitiram uma classificação tipológica precisa.

No conjunto das produções manuais contabilizam-se ainda alguns fragmentos de fundo, de base plana ou ligeiramente convexa (13 fragmentos) e um fragmento de asa, de secção oval.

Por último, cabe ainda destacar a recolha de quatro fragmentos de parede decorados. Um deles apresenta decoração plástica, com pequenas saliências na área externa, e outros três, que provavelmente correspondem a uma única peça, exibem uma decoração estampilhada com linhas paralelas de rosetas de 15 pétalas (n. ${ }^{\circ} 2361,2702,2362$ ). Deve referir-se que a presença de fragmentos de cerâmica manual com decoração estampilhada foi também documentada na área do habitat (SOUSA e ARRUdA 2014a; 2014b). 


\section{Outros objectos}

\subsection{Cossoiros e pesos}

Nos níveis de cronologia romano-republicana identificados na Urbanização do Moleão foram recuperados cinco cossoiros cerâmicos, dos quais dois apresentam decoração impressa pré-cozedura (n. ${ }^{\circ} 210$, 211).

Em termos tipológicos, dois destes objectos exibem uma forma bitroncocónica assimétrica, inserindo-se no tipo E.1 de Zaida Castro Curel (1980: 138) ou K3K1 de Luis Berrocal Rangel (1994: 203). Um deles (n. $\left.{ }^{\circ} 210\right)$ apresenta duas linhas longitudinais no topo e 11 na lateral da peça obtidas pela impressão de um elemento cordiforme. Os restantes três exemplares, de forma tendencialmente esférica, são integráveis no tipo A.2 (CASTro Curel 1980: 138) ou K3P2K1 (Berrocal RANGel 1994: 203). Destes, um (n. ${ }^{\circ}$ 211) apresenta a impressão de gramíneas no topo e na aresta superior da peça. Exemplares semelhantes a estes, tanto em forma como em técnica decorativa aplicada, surgem em contextos da 2. ${ }^{a}$ Idade do Ferro e dos alvores da romanização como El Castrejón de Capote (Berrocal Rangel 1989: 269 - fig.11), "Castro" da Azougada (Antunes 2005: 128), Cabeça de Vaiamonte (Pereira 2013), Castelo da Lousa (Pinto e Schmitt 2010: 324) ou Mesas do Castelinho (Estrela 2010: Est. 35).

Resta ainda referir a recolha de três fragmentos de pesos de produção local, que apresentam uma secção troncocónica (n. ${ }^{\circ}$ 153), podendo estar associados quer a actividades de tecelagem, quer a actividades piscícolas.

\subsection{Contas de colar de pasta vítrea}

Entre o conjunto presentemente analisado, identificaram-se três contas de pasta vítrea.

Uma delas corresponde a uma conta de perfil losangular, com digitações na parte superior e inferior, de pasta negra, possivelmente sobrecozida (n. ${ }^{\circ}$ 3852). Outra é de formato esférico, mas policroma e oculada (RuANo RuIz 1996: 70). Apresenta uma coloração azul, com oculações a branco, encontrando-se fragmentada (n. $\left.{ }^{\circ} 1713\right)$. Este tipo de conta está também documentada na Cabeça de Vaiamonte, onde 
foram identificados quatro exemplares (FABIÃo 2001: 204). As cronologias associadas a este tipo de objecto em contextos portugueses são bastante variadas, estendendo-se desde o século VI-IV a.C., como no caso do tesouro do Gaio (Sines) (Dias, Beirão e Coelho 1970) e da Cista dos Gregórios (Silves) (BARros et al. 2005), e durante toda a segunda metade do $1^{\circ}$ milénio a.C., como está patente, por exemplo, nas necrópoles de Ourique e no depósito de Garvão (Ruano RuIZ 1996: 54). No Castelo da Lousa também foi recuperada uma conta de pasta vítrea negra oculada a branco (CARVALHO 2010: 478). Exemplares semelhante surgem ainda no nível de ocupação mais recente (nível 2) de El Castrejón de Capote (Berrocal Rangel 1989: 258-259) associados a contextos datados entre os finais do século III e os finais da centúria seguinte, podendo ser, portanto, coevos aos aqui apresentados. Deve ainda referir-se a recolha de vários destes artefactos na estação do Monte Molião, infelizmente desprovidos de contexto arqueológico (Viana, Formosinho e Ferreira 1952: 139). A última conta de colar recolhida na Urbanização do Moleão (n. ${ }^{\circ}$ 3317), também de pasta vítrea, é de pequena dimensão, de formato circular e de secção semi-arredondada.

\subsection{Artefactos de osso}

No conjunto recolhido nos níveis romano-republicanos da Urbanização do Moleão, os artefactos de osso polido são raros e encontram-se em avançado estado de fragmentação, pelo que a sua representação gráfica não foi possível. Trata-se de apenas três exemplares, dois dos quais correspondem a pequenos fragmentos de secção circular que poderão ter pertencido, com grande probabilidade, a agulhas, e um outro de forma circular que poderá ter sido uma espécie de botão.

\subsection{Líticos}

Nos contextos romano-republicanos da Urbanização do Moleão foi recuperado um objecto lítico, de grauvaque (n. ${ }^{\circ}$ 3568) de forma trapezoidal e de secção sub-rectangular. A funcionalidade deste artefacto é difícil de determinar, não sendo, contudo, improvável considerar a sua utilização como uma pedra de toque.

Conimbriga, 54 (2015) 81-131 


\subsection{Outros}

Resta, por fim, referir a recolha de dois fragmentos cerâmicos (n. ${ }^{\circ} 1598$ e 2193), correspondentes, provavelmente, a uma mesma peça, que se encontram marcados por uma série de pequenas perfurações. Parece tratar-se de alguma espécie de placa que poderia ter sido utilizada em actividades de combustão, apesar de os fragmentos recuperados não exibirem marcas de exposição ao fogo. No entanto, esta ausência poderia, eventualmente, atribuir-se ao fraco estado de conservação do exemplar. Não podemos, porém, descartar a possibilidade de a peça estar associada a outras funcionalidades, relacionadas, por exemplo, com a produção ou tratamento de produtos alimentares.

\section{Conclusão}

A importância dos materiais presentemente analisados reside na confirmação de padrões e tendências de importação e produção que marcam a cultura material da fase mais antiga da ocupação romana detectada, até ao momento, ao longo da costa algarvia.

Como já foi referido anteriormente, a escassez de estudos de conjuntos de cerâmica comum de cronologias coevas (finais do séc. II / inícios do séc. I a. C.) no Sul do território português coloca algumas dificuldades em termos de uma análise comparativa. O único caso de estudo em que é possível, efectivamente, estabelecer um confronto directo ao nível das preferências e tendências da utilização da cerâmica comum provém da mesma estação arqueológica, em concreto da área de habitat do Monte Molião (Sousa e ArRuda 2014a; 2014b).

Como seria expectável, ambos os conjuntos apresentam semelhanças notáveis ao nível das diferentes produções identificadas.

Os recipientes provenientes da Baía de Cádis são claramente dominantes em ambos os conjuntos, seguindo-se as produções de âmbito local e/ou regional. Significativas são também, em ambos os casos, as produções que pensamos serem provenientes da zona do Baixo Guadalquivir (Guadalquivir A e Guadalquivir B) e também as da costa oriental da Península Ibérica, integrando exclusivamente os recipientes de tipo kalathos. As únicas diferenças significativas entre os conjuntos incidem numa maior expressividade das produções itálicas no grupo da cerâmica comum recuperada na Urbanização do Moleão e na ausência, 
nesse mesmo conjunto, de vasos provenientes da área da Campiña Gaditana. No entanto, a importância atribuível a tais divergências não deve ser excessivamente considerada, podendo simplesmente relacionar-se com fenómenos de composição e conservação dos depósitos arqueológicos ou com tendências pontuais nos quadros de importação. Cabe aqui recordar que a esmagadora maioria dos materiais presentemente estudados provem de um único contexto arqueológico (U.E. [14]), cuja formação poderá ter ocorrido num período cronológico mais curto e específico comparativamente à sequência cronológica identificada na área do habitat, o que poderia também justificar as referidas divergências.

A grande similitude entre os conjuntos verifica-se também ao nível morfológico.

Entre as produções gaditanas, que seguem tendencialmente o mesmo elenco morfológico que caracteriza a fase final do período pré-romano (SÁEz Romero 2005; Sousa 2009; Sousa e ARRUda 2010; 2014a; 2014b), as formas abertas são dominantes, em modo particular as tigelas, seguindo-se, em segundo lugar, os pratos, e, com menor frequência, as taças e bacias e/ou alguidares. No grupo das formas fechadas, os vasos de tipo pote e/ou panela ganham particular destaque, sendo as jarras e pequenos recipientes de possível uso sumptuário raros. A única diferença assinalável é a presença de grandes recipientes de tipo dolia na área do habitat, estando a forma ausente no conjunto gaditano da Urbanização do Moleão. Por último, as tampas são raras em ambos os conjuntos.

As produções do Guadalquivir A apresentam já certas discrepâncias entre os conjuntos provenientes do habitat e o da Urbanização do Moleão. No primeiro caso, a diversidade de categorias morfo-funcionais é consideravelmente mais ampla, englobando recipientes de tipo tigela, grandes taças, almofarizes, potes/panelas e tampas, formas que estão ausentes no conjunto presentemente estudado. No entanto, o tipo mais bem representado, em ambos os casos, corresponde a vasos de grande diâmetro de tipo bacia e/ou alguidar, seguindo-se, com menor expressão, os recipientes de tipo dolia. Tendo em conta as dimensões dos principais recipientes cerâmicos detectados nos dois conjuntos, não é impossível considerar que esses vasos possam ter sido inicialmente utilizados enquanto contentores de transporte de produtos alimentares (oleícolas ou vinícolas) do interior da Andaluzia, numa fase prévia à do desenvolvimento das produções anfóricas nessa mesma área, que se 
iniciará apenas a partir de finais do $1^{\circ}$ quartel do século I a.C. (Sousa e ARruda 2014b: 70).

Em relação às produções designadas por Guadalquivir B, relacionáveis, provavelmente, com horizontes culturais de matriz turdetana (Sousa e ARruda 2014b: 74) é observável uma maior proximidade morfológica entre os dois conjuntos, ambos dominados pelas formas fechadas de tipo pote e/ou panela, seguidas pelas tigelas, bacias e/ou alguidares e pelas taças. Os pratos e as jarras estão ausentes no conjunto da Urbanização do Moleão sendo, contudo, também pouco expressivos na área do habitat. A mesma situação verifica-se com as tampas representadas por um único exemplar no conjunto presentemente estudado e ausente no povoado.

A análise comparativa dos conjuntos de cerâmica comum produzida na Península Itálica é aquela que apresenta uma maior discrepância. Como já foi referido anteriormente, este tipo de recipientes são consideravelmente mais abundantes nos contextos romano-republicanos da Urbanização do Moleão do que na área de habitat. No entanto, esta maior expressividade quantitativa não se traduz num repertório morfológico mais abrangente. Com efeito, e apesar do seu número mais reduzido, o conjunto de cerâmica comum itálica do habitat apresenta uma variedade formal muito mais acentuada, contando com patellae, caccabi, almofarizes e pratos de cerâmica de engobe vermelho pompeiano (Sousa e ARRUda 2014a; 2014b), enquanto que os tipos recolhidos durante as escavações realizadas na Urbanização do Moleão se resumem apenas a patinae e respectivas tampas.

No grupo das produções de âmbito local e/ou regional voltamos a observar grandes semelhanças entre os conjuntos.

Entre as produções a torno, destaca-se a predominância dos vasos de tipo pote e/ou panela, que seriam possivelmente utilizados sobretudo na confecção de alimentos, atendendo às frequentes marcas de exposição ao fogo que evidenciam as suas superfícies externas. Deve ainda destacar-se a existência de algumas morfologias deste grupo que parecem inspirar-se directamente nos modelos itálicos, uma evidência que permite atestar o impacto do processo da romanização na alteração dos hábitos alimentares (Sousa e Arruda 2014a; 2014b). Seguem-se, com menor abundância, as tigelas, bacias e/ou alguidares, grandes contentores de tipo dolia, tampas e taças de pequena dimensão, cujas formas parecem copiar os protótipos da Andaluzia meridional. Por último, deve referir-se que o conjunto proveniente da área do habitat 
exibe ainda uma maior diversidade morfológica, contando com alguns exemplares de pratos e de jarros que estão ausentes na Urbanização do Moleão.

Uma situação semelhante à anterior é verificável também no grupo das produções manuais, dominadas por recipientes fechados de tipo pote e/ou panela. Esta tendência relaciona-se, muito provavelmente, com a necessidade de fabricar recipientes aptos sobretudo à confecção de alimentos (SousA e ArRUDA 2014b: 85), possivelmente para suprimir carências pontuais de outras produções destinadas a essa finalidade. Outras morfologias, possivelmente utilizadas também no processo de confecção de alimentos, como as tigelas/taças, são raras no conjunto. No conjunto da Urbanização do Moleão, deve ainda destacar-se a recolha de uma tampa e a ausência de jarros, forma relativamente bem documentada na área do habitat (SousA e ARRUDA 2014a; 2014b). Um dos elementos mais relevantes no grupo das produções manuais é, sem dúvida, a recolha de fragmentos decorados com decoração estampilhada, uma realidade característica sobretudo das comunidades da "área celtizante" do Sul do território português (ARNAUD e Gamito 1974-1977; Berrocal Rangel 1992; Fabiẽo 1998). A sua presença na Urbanização do Moleão e também na área do habitat (SOUSA e ARRUDA 2014a; 2014b) poderia causar alguma perplexidade considerando que esta tradição não se encontra atestada, pelo menos ao nível das produções manuais, no horizonte cultural algarvio do período pré-romano. A introdução destes elementos durante a fase romana-republicana poderá relacionar-se quer com fenómenos de comércio inter-regional que atingem uma maior difusão durante este período, quer com a presença de agentes originários da dita "área céltica" no Sudoeste algarvio durante a fase de romanização do território (SousA e ARRUDA 2014a; 2014b).

Contudo, e partindo de uma perspectiva mais globalizante, cabe destacar, por um lado, a grande variedade de centros abastecedores de cerâmica comum e, por outro, a esmagadora presença de materiais provenientes da actual Andaluzia, particularmente da Baía gaditana, uma tradição que se verifica já durante a fase final da Idade do Ferro e que continua a ser uma realidade durante o período romano-republicano. Essa tradição verifica-se não só em termos das áreas de produção, mas também ao nível do consumo, considerando que estas formas sul-peninsulares seguem tendências morfológicas que recuam à fase pré-romana, sendo escassos os indicadores de influências itálicas. 
No entanto, essa mesma influência encontra-se mais claramente manifestada em outros conjuntos de cerâmica comum da estação do Monte Molião, quer através da importação de cerâmicas de cozinha de origem itálica, quer na presença, entre os materiais de produção local, de vasos destinados à confecção de alimentos com características morfológicas que recordam outras formas tipicamente romanas. Estas evidências parecem, efectivamente, refletir que as comunidades que habitaram o Monte Molião durante o período romano republicano se encontravam já numa fase avançada do processo de romanização (SousA e ARRUDA 2014a; 2014b).

Em relação aos restantes objectos aqui estudados, deve destacar-se a presença de indicadores directamente relacionados com actividades de tecelagem (cossoiros, pesos de tear (?) e fragmentos de agulhas de osso polido), e também de alguns objectos de adorno de pasta vítrea (contas de colar). Em relação a estes últimos, destaca-se a presença de uma conta de colar oculada. A existência destes materiais em contextos de cronologia republicana não é inédita, como se verifica no Castelo da Lousa (CARVAlHo 2010: 478). No entanto, a possibilidade de se tratar de uma peça residual não é de excluir, considerando que a estação arqueológica tem uma importante ocupação pré-romana (ARRUDA et al. 2008; 2011). Também interessa aqui destacar a recolha de objectos de funcionalidade mais duvidosa (a possível "pedra de toque" e a placa cerâmica com perfurações) mas que poderão, eventualmente, relacionar-se com algum tipo de actividade artesanal metalúrgica, que terá ocorrido nessa área. A este respeito, deve referir-se que, durante a escavação dos contextos de cronologia romano-republicana, foram recolhidos vários quilos de escória em associação aos restantes materiais.

A realidade arqueológica romano-republicana detectada na área exterior ao povoado de Monte Molião, e inclusive na área externa de um segmento de fosso, identificado nas proximidades (DIOGO e MARQuES 2008), que delimitaria pelo menos parte da área habitacional, é de difícil caracterização, atendendo ao facto de terem sido documentadas exclusivamente estruturas negativas. Poder-se-ia, eventualmente, considerar que esta área externa da estação arqueológica de Monte Molião poderia ter sido utilizada para o escoamento de lixos domésticos e resíduos alimentares produzidos no habitat ou então (ou simultaneamente) para a realização de actividades específicas, de natureza eventualmente metalúrgica, a julgar pelas evidências anteriormente referidas. 


\section{BIBLIOGRAFIA}

Alves, Catarina; Sousa, Elisa e Pereira, Teresa (no prelo) - A cerâmica fina romano-republicana da Urbanização do Moleão (Lagos, Portugal).

Antunes, Ana Sofia (2005) - Castro da Azougada - conjunto cerâmico. Em torno da Idade do Ferro Pós orientalizante da margem esquerda do Baixo Guadiana. Dissertação de Mestrado em Pré-História e Arqueologia [texto policopiado]. Lisboa: Faculdade de Letras da Universidade de Lisboa.

Arcelin, Patrice e Tuffreau-Libre, Marie (Dir.) (1998) - La quantification des céramiques. Conditions et protocole. Actes de la table ronde du Centre archéologique européen du Mont Beauvray (Glux-en-Glenne, 7-9 avril 1998), Bibracte, 2.

Arnaud, José e Gamito, Teresa (1974/1977) - Cerâmicas estampilhadas da Idade do Ferro do sul de Portugal. I - Cabeça de Vaiamonte - Monforte. O Arqueólogo Português 3 7-9, p. 165-202.

ArrudA, Ana Margarida; SousA, Elisa; BARgão, Patrícia e Lourenço, Pedro (2008) Monte Molião (Lagos): resultados de um projecto em curso. Xelb 8-1, p. 137-168.

Arruda, Ana Margarida; Sousa, Elisa; Pereira, Carlos e Lourenço, Pedro (2011) Monte Molião: um sítio púnico-gaditano no Algarve (Portugal). Conimbriga 50, p. 5-32.

Barros, Pedro; Branco, Gertrudes; Duarte, Cidália e Correia, Jorge (2005) - A Cista dos Gregórios (Silves). Xelb 5, p. 41-52.

BATs, Michel (1993) - Céramique commune italique. Dictionnaire des céramiques antiques (VIIes. de n.è.) en Méditerranée nord-occidentale. Lattara 6, p. 357-362.

Berrocal Rangel, Luís (1989) - El asentiamento «céltico» del Castrejón de Capote (Higuera la Real, Badajoz). CuPAUM 16, p. 245-296.

Berrocal Rangel, Luís (1992) - Los pueblos célticos del Suroeste de la Península Ibérica, Complutum Extra, Madrid.

Berrocal Rangel, Luís (1994) - El altar prerromano del Castrejón del Capote: ensayo etno-arqueológico de un ritual céltico en el suroeste peninsular. Madrid: Universidad Autónoma de Madrid.

Carvalho, Pedro (2010) - Capítulo 7.8 - Vidros. In Alarcão, Jorge, Carvalho, Pedro, Gonçalves, Ana (coord.): Studia Lusitana, 5 - Castelo da Lousa: intervenções arqueológicas de 1997 a 2002, Mérida, p. 481-517.

Castro Curel, Zaida (1980) - Fusayolas ibéricas, antecedentes y empleo. Cypsela 3, p. 127-145.

Conde Berdós, Maria José (1991) - Les produccions de kálathoi d’Empúries i la seva difusió mediterrània (segles II-I a.n.e.), Cypsela 9, p. 141-168.

Conde Berdós, Maria José (1998) - Estado actual de la investigación sobre la ceramic ibérica pintada de época plena y tardía, Revista de Estudios Ibéricos 3, p. 299-335.

Dias, Maria Manuela; Beirão, Caetano de Melo e Coelho, Luís (1970) - Duas necropolis da Idade do Ferro no Baixo-Alentejo: Ourique (notícia preliminar), $O$ Arqueólogo Português 3-4, p. 175-219.

Conimbriga, 54 (2015) 81-131 
Diogo, Mária e Marques, João (2008) - Sistemas defensivos do Molião - resultados preliminares da intervenção arqueológica na urbanização do Molião. Xelb 8-2, p. 59-65.

Estrela, Susana (2010) - Niveis fundacionais da Idade do Ferro de Mesas de Castelinho (Almodôvar). Os contextos arqueológicos na (re)construção do povoado. Tese de mestrado [texto policopiado]. Lisboa: Faculdade de Letras da Universidade de Lisboa.

FABĨ̃o, Carlos (1998) - O Mundo Indígena e a sua Romanização na área Céltica do território hoje português, Dissertação de Doutoramento apresentada à Faculdade de Letras da Universidade de Lisboa, edição policopiada.

FABĨ̃o, Carlos (2001) - Importações de origem mediterrânea no interior do sudoeste peninsular na segunda metade do I milénio a.C.: materiais de Cabeça de Vaiamonte, Monforte. In Os púnicos no Extremo Ocidente, Lisboa: Universidade Aberta, p. 197-227.

Ferrer Albelda, Eduardo e García Fernández, Francisco José (2008) - Cerámica turdetana. In Bernal Casasola, Dario e Ribera i Lacomba, Albert, Cerámicas hispanorromanas. Un estado de la cuestión, Cádis: Universidade, p. 201-219.

García Vargas e García Fernandez, Enrique (2009) - Romanización y consumo: cámbios y continuidades en los contextos cerámicos de Hispalis en épocas turdetana y romano-republicana, Spal 18, p. 131-165.

García Fernandez, Francisco José (2015) - El peso de la tradición: imitación y adaptación de formas helenísticas en la cerámica común turdetana (siglos V-I a.C.). In García Fernandez, Francisco José, García Vargas, Enrique (eds.), Comer a la moda. Imitaciones de vajilla de mesa en Turdetania y la Bética ocidental durante la Antiguedad (s. VI a.C. - VI d.C.), Barcelona, p. 205-237.

García Fernandez, Francisco José e García Vargas, Enrique (2010) - Entre gaditanización y romanización: repertórios cerâmicos, alimentación e integración cultural en Turdetania (siglos III-I a.C.). In Mata Parreño, Consuelo; PéreZ Jordà, Guillem e Vives-Ferrándiz SÁnchez, J. (eds.), De la cuina a la taula, Valência: Universidade, p. 115-134.

MAIA, Maria (2007) - La pesca, a actividade conserveira e as ânforas de Tavira. In Historia de la pesca en el ámbito del Estrecho, I, p. 455-488.

Muccioli, Giovanni (2014) - I Kalathoi Iberici nell Éstremo Occidente. In Rei Cretariae Romanae Fautorum Acta 43, p. 721-728.

Muscolino, Francesco (2006) - Kalathoi iberici da Taormina. Aggiornamento sulla diffusione della cerâmica ibérica dipinta in Sicilia, Archivo Español de Arqueología 79, p. 217-224.

Niveau de Villedary y Mariñas, Ana Maria (2003) - El uso ritual de la vajilla cerámica en la necrópolis púnica de Cádiz, Archivo Español de Arqueología 76, p. 3-30.

Niveau de Villedary y Mariñas, Ana Maria (2004) - Las Cerámicas Gaditanas "Tipo Kuass”. Bases para el análisis de la Bahía de Cádiz en época púnica. Cádiz: Universidad.

Conimbriga, 54 (2015) 81-131 
Niveau de Villedary y Mariñas, Ana Maria (2009) - Ofrendas, banquetes y libaciones. El ritual funerário en la necrópolis púnica de Cádis. Sevilha.

Pereira, T. (2013) - Por um fio: tipologia e função do conjunto de cossoiros de Cabeça de Vaiamonte (Monforte, Portugal). In Arnaud, J.M., Martins, A., Neves, C. (coord.), Arqueologia em Portugal. 150 anos. Actas do I Congresso da Associação dos Arqueólogos Portugueses, Lisboa, p. 681-691.

Pereira, Teresa; Alves, Catarina e Sousa, Elisa (2015) - Metallic artifacts from the outside area of Monte Molião (Lagos, Portugal). In Álvarez, José Maria, Nogales, Trinidad e RodÀ, Isabel (eds.), Actas del XVIII Congreso Internacional de Arqueología Clásica, vol. 2, Mérida, p. 1751-1755.

PINTo, Inês Vaz (2004) - Cerâmica comum de provável origem bética das villae romanas de São Cucufate. Lusíada. Arqueologia, História de Arte e Património 2/4, p. 9-29.

Pinto, Inês Vaz; Schmitt, Anne (2010) - Capítulo 7.6 - Cerâmica Comum. In Alarcão, Jorge, Carvalho, Pedro, Gonçalves, Ana (coord.), Studia Lusitana, 5 - Castelo da Lousa: intervenções arqueológicas de 1997 a 2002, Mérida, p. 219-443.

Ribera i LaCOMBA, Albert e MARÍN JoRdá, Carmen (2003) - Las importaciones itálicas del nível de fundación (138 a.C.) de la ciudad romana de Valentia. In Rei Cretariae Romanae Fautorum Acta 38, p. 287-294.

Ribera, Albert (2010) - Depósitos rituales de Valentia (Hispania): de la primera fundación republican (138 a.C.) a la segunda augustea. In Di GiUSEPPE Helga e SELORENZI Mirella (eds.), I riti del costruire nelle acque violate, Roma, p. 269-294.

RuAno RuIz, Encarnación (1996) - Las cuentas de vidrio prerromanas del museo arqueológico de Ibiza y Formentera. Eivissa: Museu Arqueològic d'Eivissa i Formentera.

SÁEz Romero, António (2005) - Aproximación a la tipología de la cerámica común púnico-gadirita de los ss. III-II. Spal 14, p. 145-177.

SÁez Romero, António (2008) - La producción cerámica en Gadir en época tardopúnica (siglos -III/-I). Oxford: BAR International Series S1812.

SÁEz Romero, António (2014) - Imitaciones en las vasijas de mesa en la Bahía de Cádiz desde la transición tardoarcaica hasta la época tardopúnica. Actualización de los datos y nuevas propuestas. In García Fernandez, Francisco José, García VARgas, Enrique (eds.), Comer a la moda. Imitaciones de vajilla de mesa en Turdetania y la Bética ocidental durante la Antiguedad (s. VI a.C. - VI d.C.), Barcelona, p. 33-77.

Sousa, Elisa (2009) - A cerâmica de tipo Kuass no Algarve, Cadernos da Uniarq, 4, Centro de Arqueologia da Universidade de Lisboa.

Sousa, Elisa e Arruda, Ana Margarida (2010) - A gaditanização do Algarve. Mainake 32-2, p. 951-974.

Sousa, Elisa e Arruda, Ana Margarida (2014a) - Italics and Hispanics in Southwest Iberia in the Dawn of the Roman-Republican period: the common ware of Monte Molião (Lagos, Portugal). In Rei Cretariae Romanae Fautorum Acta 43, p. 663-670.

Conimbriga, 54 (2015) 81-131 
SousA, Elisa e ArrudA, Ana Margarida (2014b) - A cerâmica comum romano-republicana de Monte Molião (Lagos). Onuba 2, p. 55-90.

Sousa, Elisa e SERRA, Miguel (2006) - Resultados das intervenções arqueológicas realizadas na zona de protecção do Monte Molião (Lagos). Xelb 6-1, p. 5-20.

Sousa, Elisa; Alves, Catarina e Pereira, Teresa (no prelo) - O conjunto anfórico da Urbanização do Moleão (Lagos, Portugal).

Tarradell, Michel e Sanmartí, Enric (1980) - L'état actuel des ètudes sur la céramique ibérique, Céramique Hellénistiques et Romaines, Centre de Recherches d'Histoire Ancienne 36- Annales Littéraires de l'Université de Besançon, 242, p. 303-330.

Vegas, Mercedes (1973) - Cerámica común romana del Mediterráneo Occidental, Barcelona.

Viana, Abel; Formosinho, José e Ferreira, Octávio da Veiga (1952) - Alguns objectos inéditos do Museu Regional de Lagos. Monte Molião. Revista de Guimarães 62 $1: 2$, p. 133-142. 

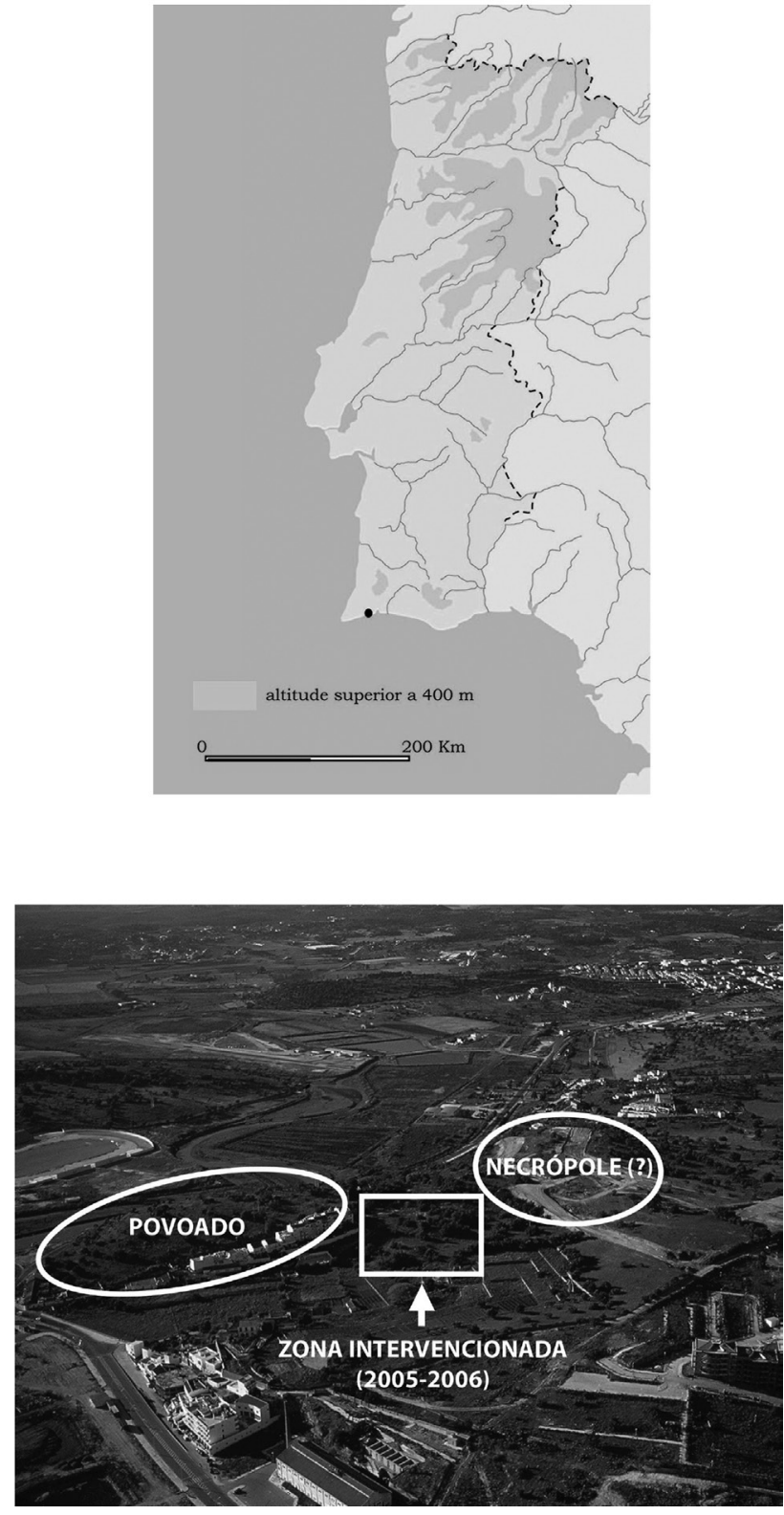

Fig. 1 - Localização da Urbanização do Monte Moleão (base cartográfica de V. Gonçalves) e vista aérea da zona intervencionada (foto de Rui Parreira - IPPAR). 


\begin{tabular}{|c|c|}
\hline $\begin{array}{|ll|}\text { Escala } & \\
0 \mathrm{~m} & 0,4 \mathrm{~m} \\
\end{array}$ & $\begin{array}{l}\text { Cliente } \\
\text { Moleăo - Sociedade de } \\
\text { Investimentos Turisticos, Lda }\end{array}$ \\
\hline $\begin{array}{l}\text { Desenhos } \\
\text { Elisa de Sousa } \\
\text { Catarina Alves } \\
\end{array}$ & \begin{tabular}{|l|} 
Projecto \\
Urbanizaçáo de Loteamento \\
sito no Moleão - Lagos \\
\end{tabular} \\
\hline $\begin{array}{l}\text { Contexto } \\
\text { Sondagem } 1 \\
\text { U.E.[18] }\end{array}$ & $\frac{M_{0}}{\text { palimpsesto }} \times$ \\
\hline
\end{tabular}

- - -Área intervencionada em 2006

- - -Área intervencionada em 2005

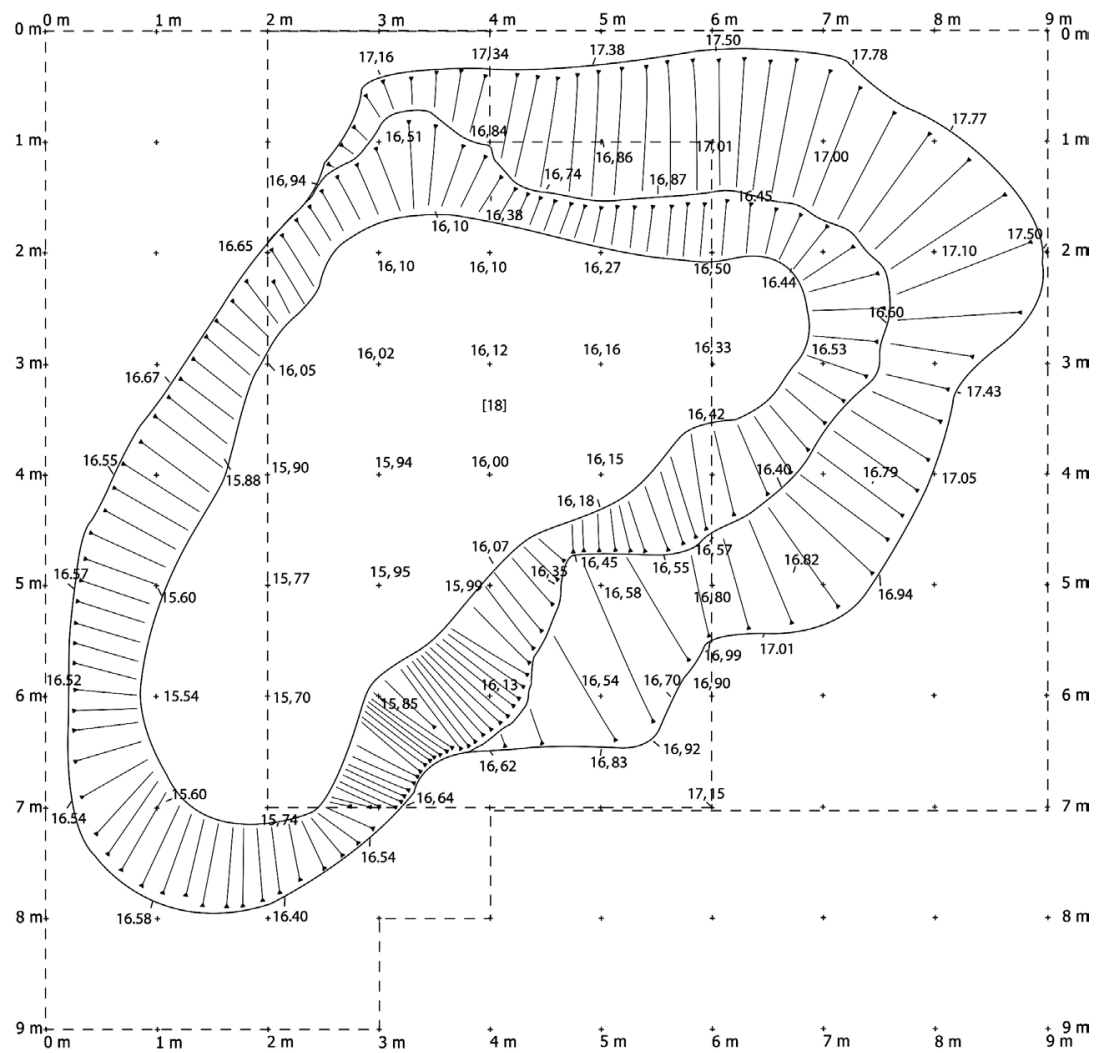

FIG. 2 - Planta da estrutura negativa U.E. [18]. 


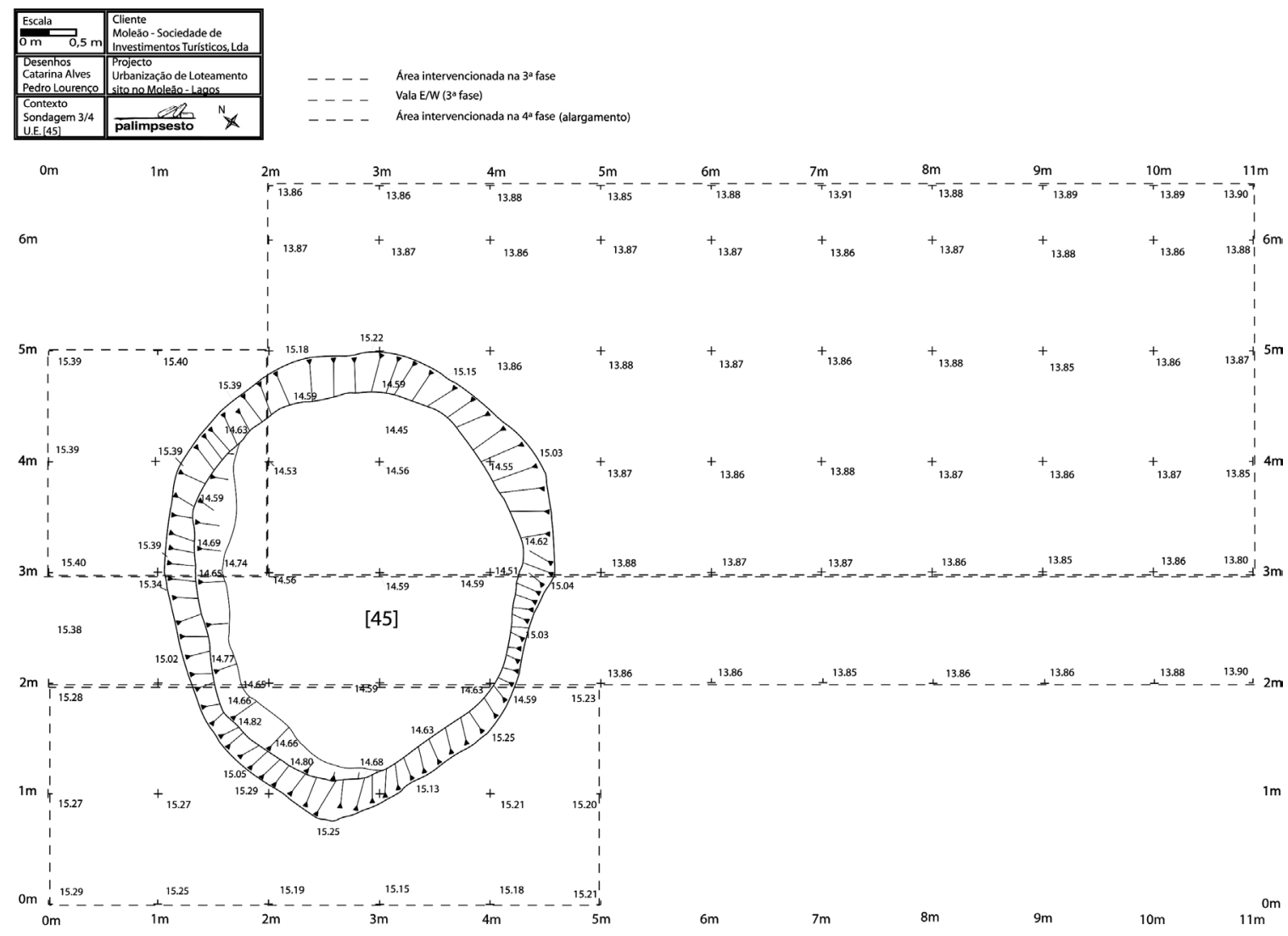

FIG. 3 - Planta da estrutura negativa U.E. [45]. 


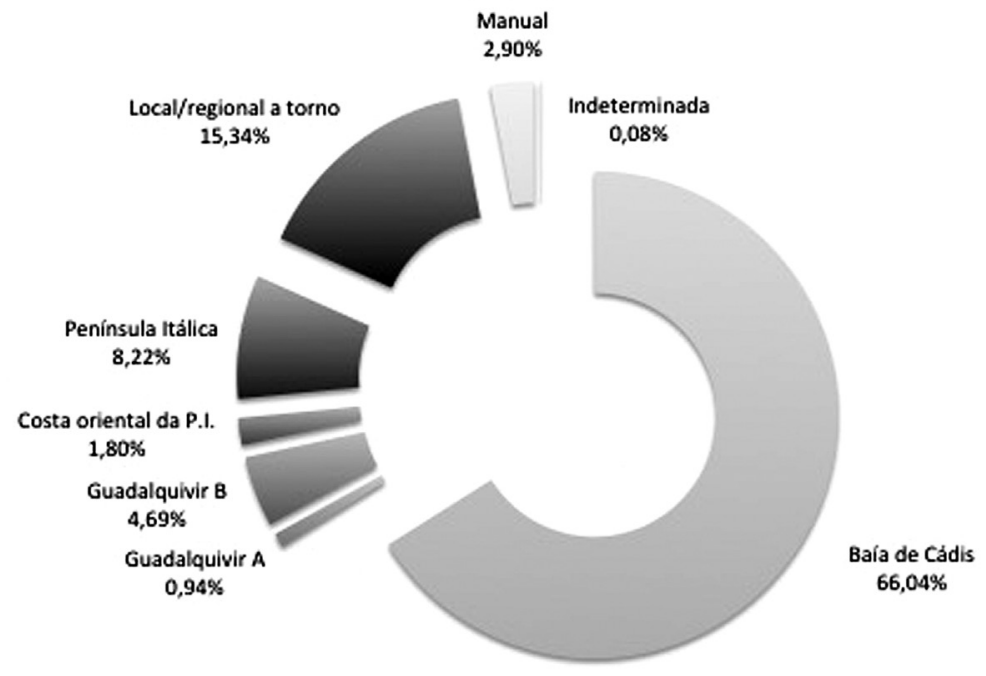

FIG. 4 - Distribuição das diversas produções identificadas no conjunto de cerâmica comum recolhido em niveis republicanos (base NMI). 


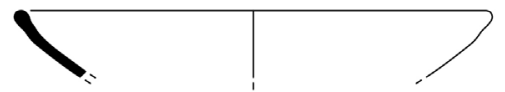

192 [14]

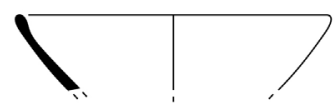

2605 [14]

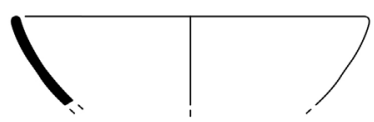

186 [14]

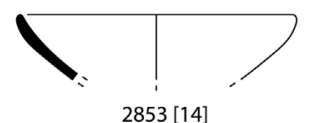

$2853[14]$

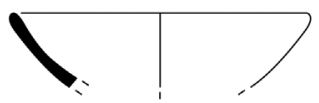

1801 [14]

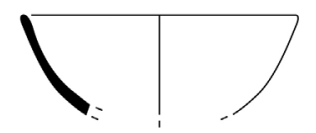

$3702[14]$

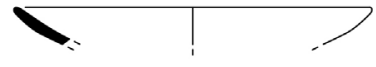

184 [14]

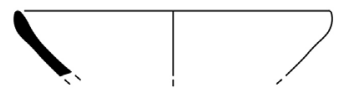

193 [14]

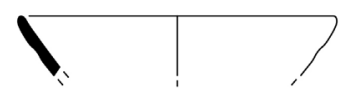

183 [14]

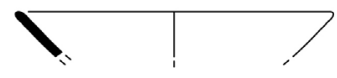

185 [14]

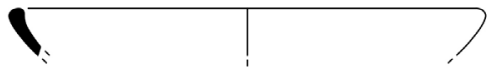

191 [14]

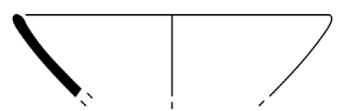

2749 [14]

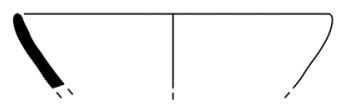

189 [14]

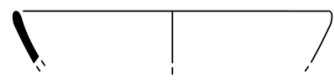

190 [14]

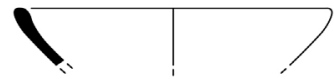

187 [14]

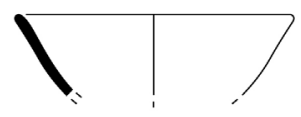

1802 [14]

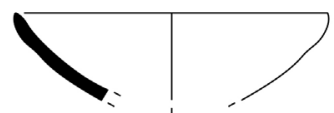

2847 [14]

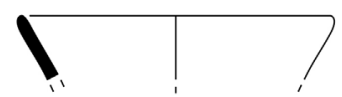

2914 [14]

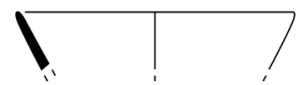

2849 [14]

FIG. 5 - Urbanização do Moleão: tipo GDR 1.2.1 (192, 191, 2605, 2749 , 186, 189, 2853, 190, 1801, 187, 3702, 1802, 184), GDR 1.2.2 (193, 2847) e GDR 1.2.3 (183, 2914, 185, 2849) de produção gaditana. 


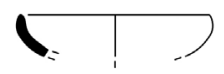

3085 [14]

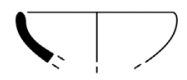

3536 [14]

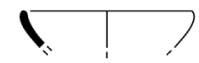

3144 [14]

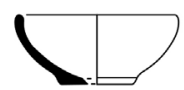

3142 [14]

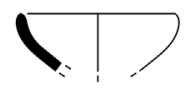

2007 [14]

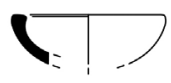

195 [14]

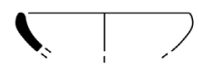

2480 [14]

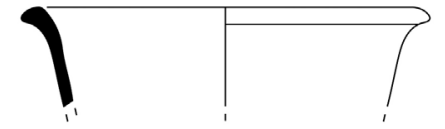

70 [14]

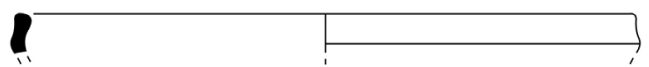

75 [14]

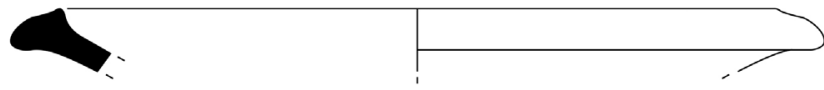

38 [14]
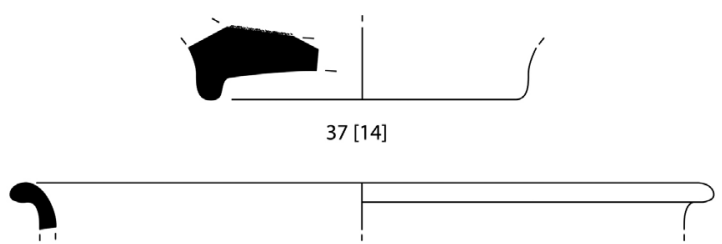

1934 [14]

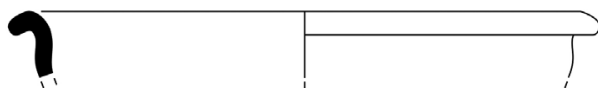

1869 [14]

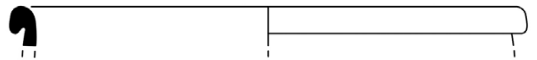

2874 [14]

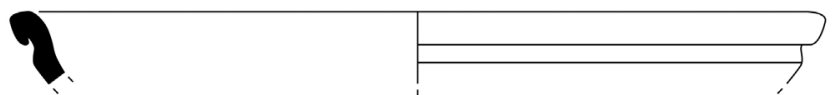

57 [14]

FIG. 6 - Urbanização do Moleão: tipo GDR 1.1.1 (3085),

GDR 1.1.2 (3142, 195, 3536, 2007, 2480, 3144), taça (70), tipo GDR 2.1.1. (75), 3.1. (38, 37), alguidares de perfil hemisférico $(1934,1869)$ e carenado $(2874,57)$ de produção gaditana. 


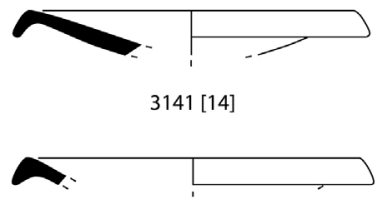

2815 [14]

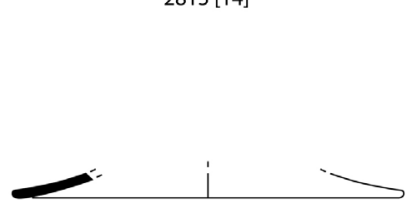

1877 [14]

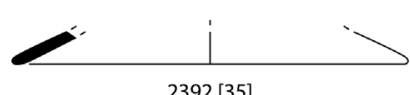

2392 [35]

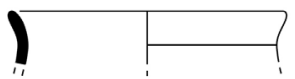

2149 [14]

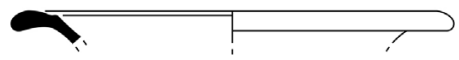

3146 [14]

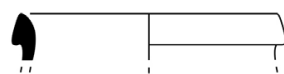

2648 [14]

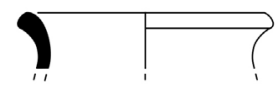

2641 [14]

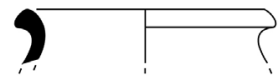

2634 [14]

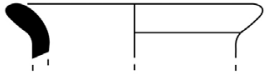

61 [14]

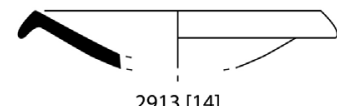

2913 [14]

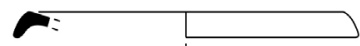

2829 [14]

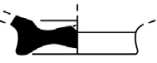

2755 [14]

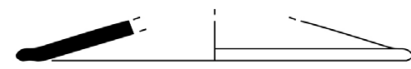

1293 [35]
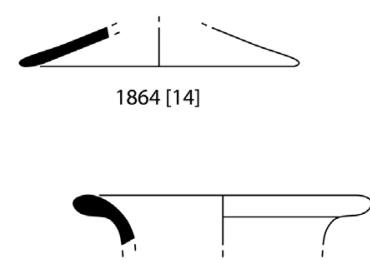

2252 [14]

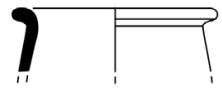

768 [14]

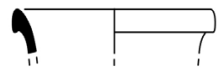

2241 [14]

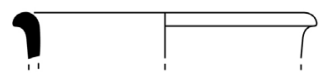

65 [14]

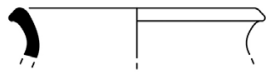

1124 [14]

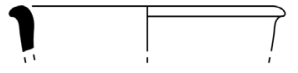

74 [14] $10 \mathrm{~cm}$

Fig. 7 - Urbanização do Moleão: tipo GDR 5.1. (3141, 2913, 2815, 2829, 2755) e tampas $(1877,1293,2392,1864)$ e potes / panelas $\left(n .^{\circ} 2149,61,2252,3146\right.$, $768,2648,77,2241,2641,1900,65,2634,1124,74)$ de produção gaditana. 


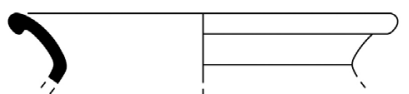

69 [14]

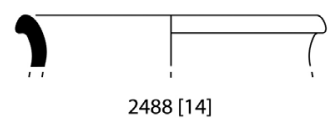

2488 [14]

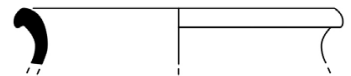

2906 [14]

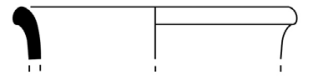

2029 [14]

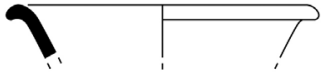

67 [14]

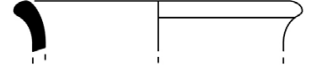

72 [14]

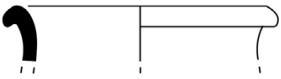

2054 [14]

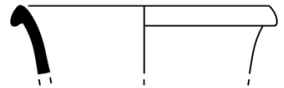

2768 [14]

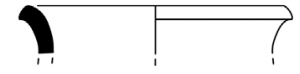

2823 [14]
2373 [14]
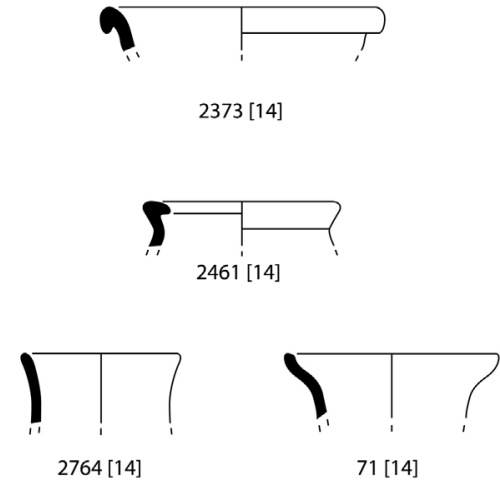

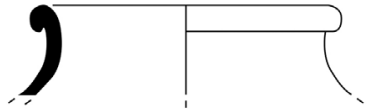

63 [14]

2085 [14]

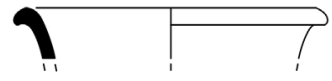

2370 [14]
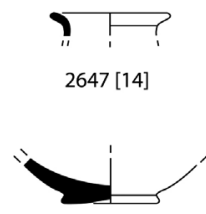

2369 [14]
182 [14]
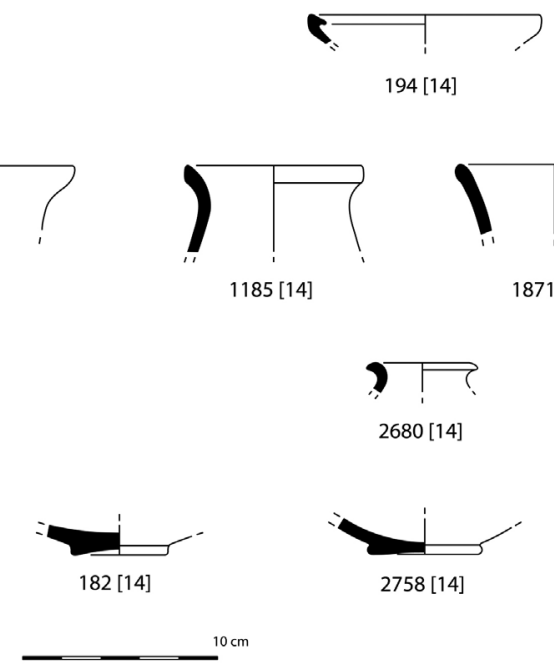

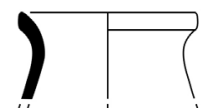

1185 [14]

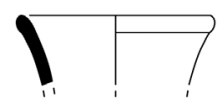

1871 [14]

Fig. 8 - Urbanização do Moleão: potes / panelas (69, 2488, 2906, 72, 2823, 2029, 2054, 2085, 67, 2768, 2370, 2373, 63, 2461, 194), tipo GDR $10(2764,71,1185,1871)$ e vasos de pequena dimensão $(2647,2680)$ e fundos $(2369,182,2758)$ de produção gaditana. 


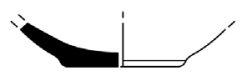

$2346[14]$

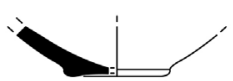

2078 [14]

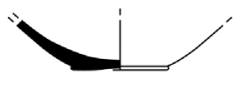

116 [14]

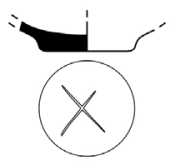

115 [14]

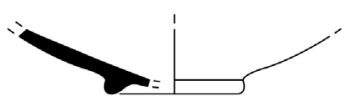

2380 [14]

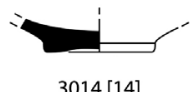

3014 [14]

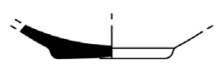

2069 [14]

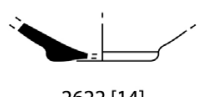

$2622[14]$

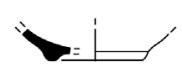

2079 [14]

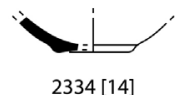

$2334[14]$

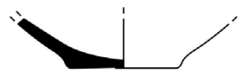

2804 [14]
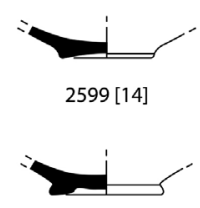

2337 [14]

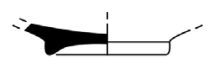

2627 [14]

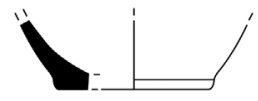

2748 [14]

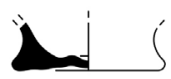

117 [14]

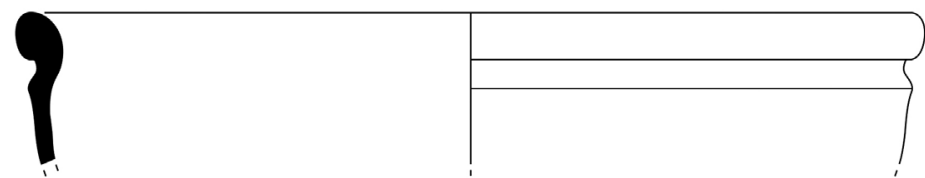

2601 [14]

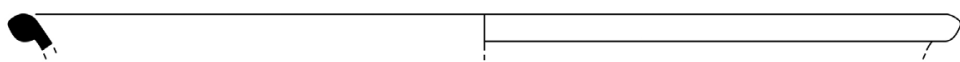

3020 [14]

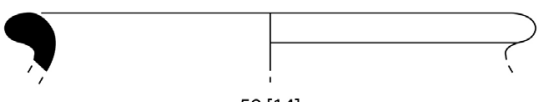

59 [14]

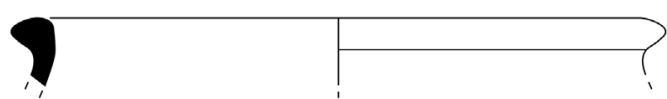

66 [14]

$10 \mathrm{~cm}$

FIG. 9 - Urbanização do Moleão: fundos (2346, 3014, 2334, 2078, 2069, 2804, 116, 2622, $2599,115,2079,2337,2627,2380,2748,117)$ de produção gaditana; alguidares $(2601,3020)$ e grandes recipientes tipo dolia $(59,66)$ do Guadalquivir A. 

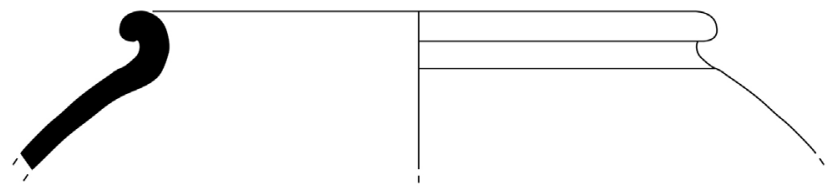

73 [14]

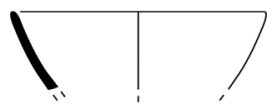

$1855[14]$

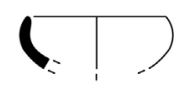

$2203[14]$

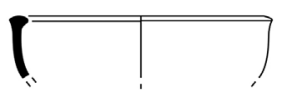

$2825[14]$

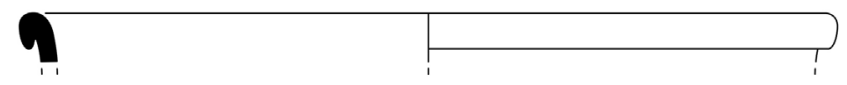

$2742[14]$

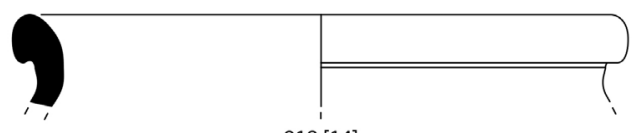

918 [14]
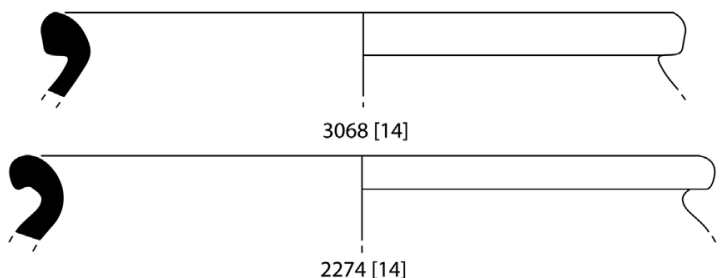

$2274[14]$
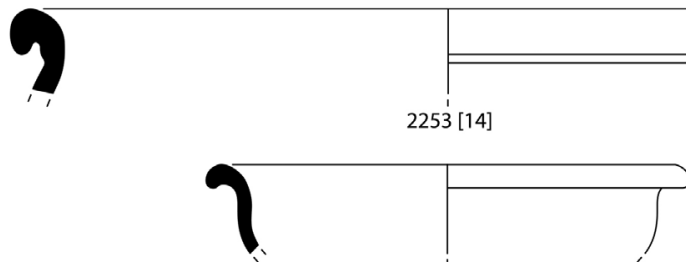

919 [14]

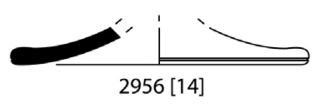

2956 [14] $10 \mathrm{~cm}$

Fig. 10 - Urbanização do Moleão: grande recipiente tipo dolia (73) do Guadalquivir A; tigela (1855), taças (2203, 2825), bacias elou alguidares (2742, 918, 3068, 2274, 2253,

919) e tampa (2956) do Guadalquivir B. 


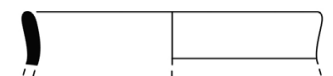

1147 [14]

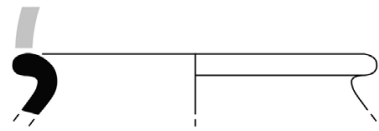

2247 [14]

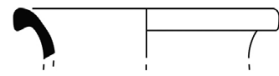

2535 [14]

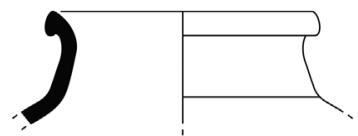

2596 [14]

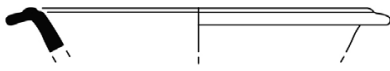

2209 [14]

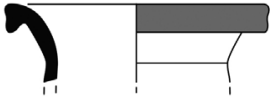

2745 [14]

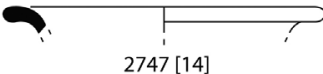

2747 [14]

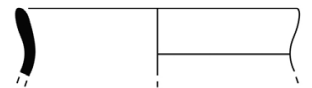

2533 [14]

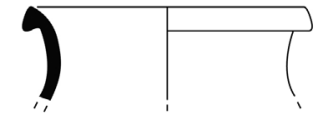

$1858[14]$

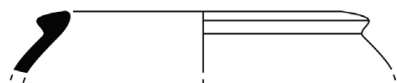

2774 [14]

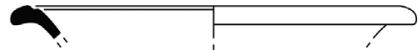

$2744[14]$

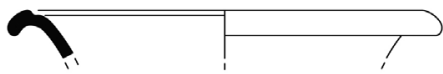

2462 [14]

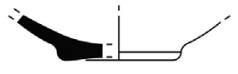

2256 [14]

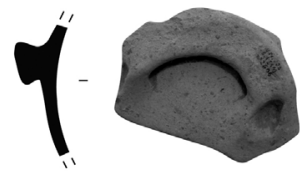

2700 [14]

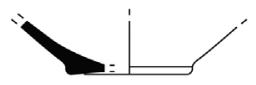

1906 [14]

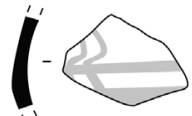

2368 [14]
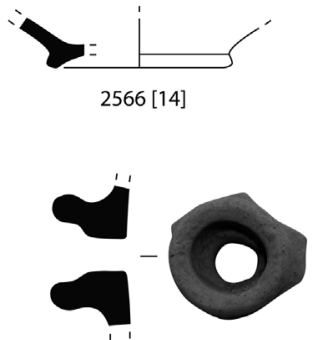

2000 [14]

Fig. 11 - Urbanização do Moleão: potes / panelas (1147, 2533, 2247, 2747, 2535, $2745,1858,2596,2774,2209,2744,2462)$, fundos (2256, 1906, 2566), asa (2700), vertedor (2000) e parede pintada (2368) do Guadalquivir B. 


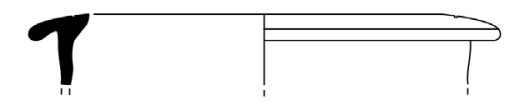

3087 [14]

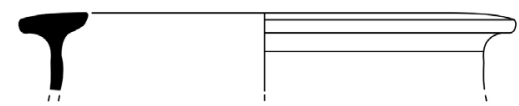

2621 [14]

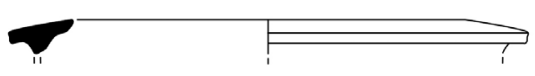

2900 [14]
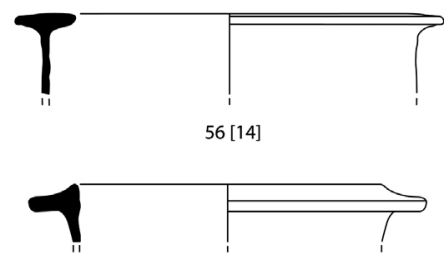

1901 [14]

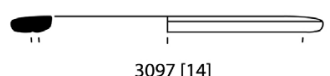

3097 [14]

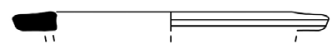

2902 [14]
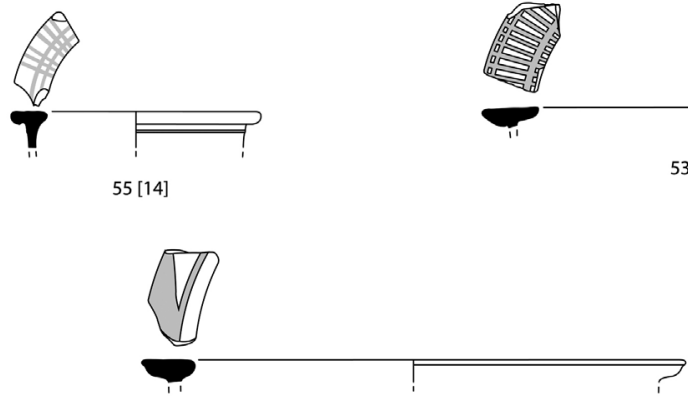

54 [14]

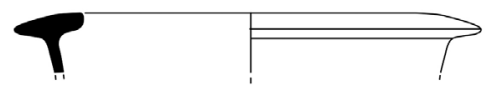

3086 [14]
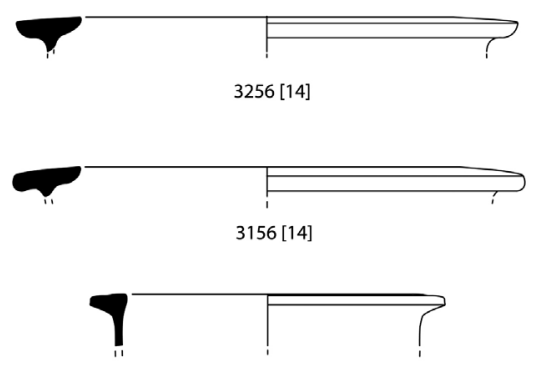

52 [14]

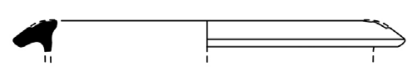

1586 [14]

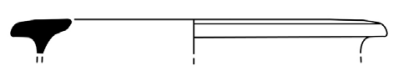

3302 [14]

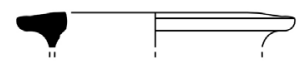

1897 [14]

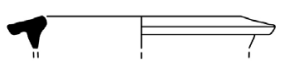

3145 [14]

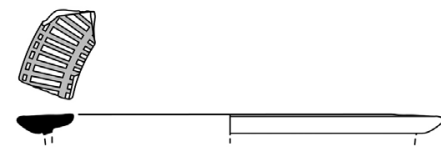

53 [14] 

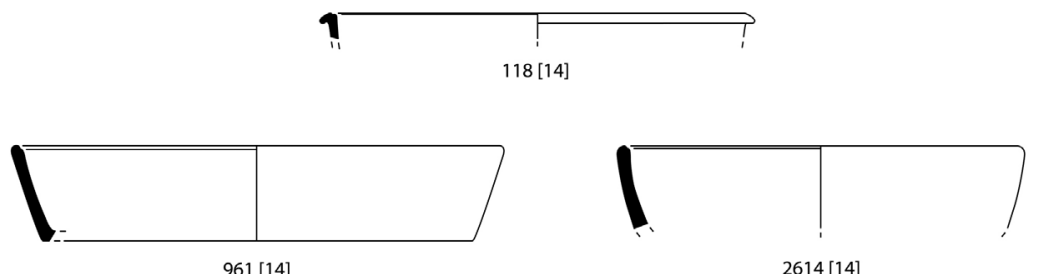

$961[14]$

2614 [14]

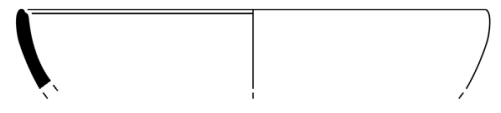

$2701[14]$

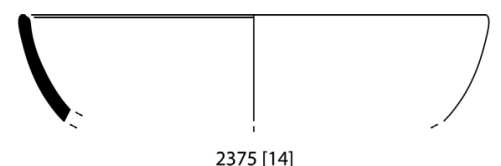

$2375[14]$

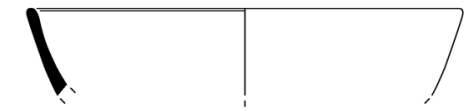

$2381[14]$

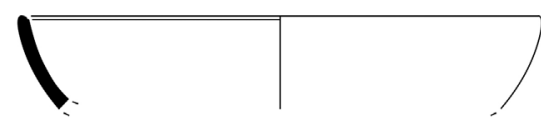

$1822[14]$
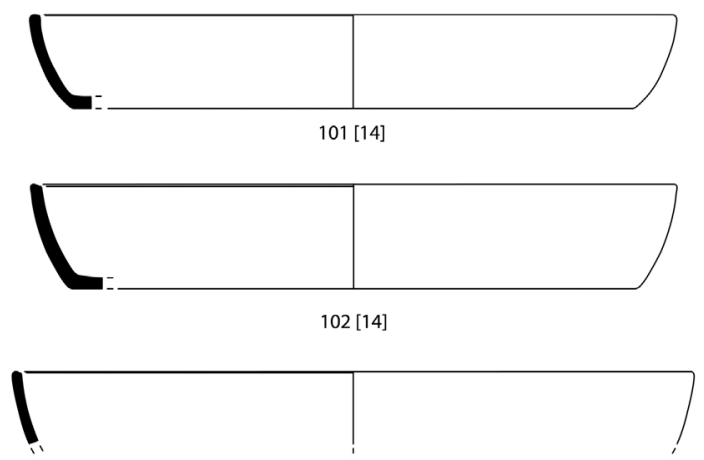

105 [14]

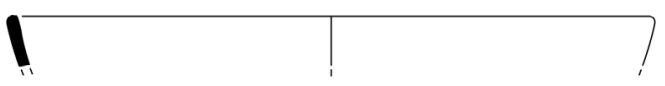

$114[14]$

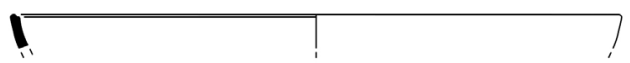

111 [14] $10 \mathrm{~cm}$

Fig. 13 - Urbanização do Moleão: tipo COM-IT $6 b$ (118) e $6 c(961,2614,2701,2381,2375,1822,101,102,105,114,111)$ de produção itálica. 


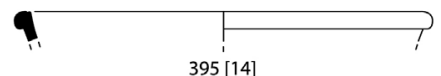

$395[14$

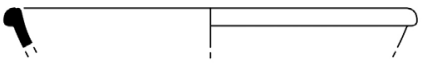

392 [14]
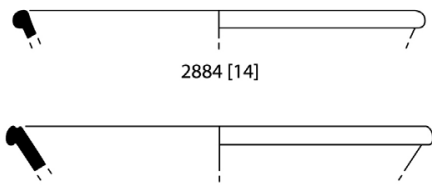

2553 [14]

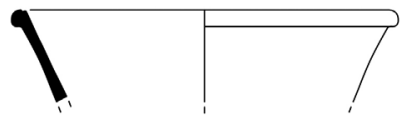

1966 [14]
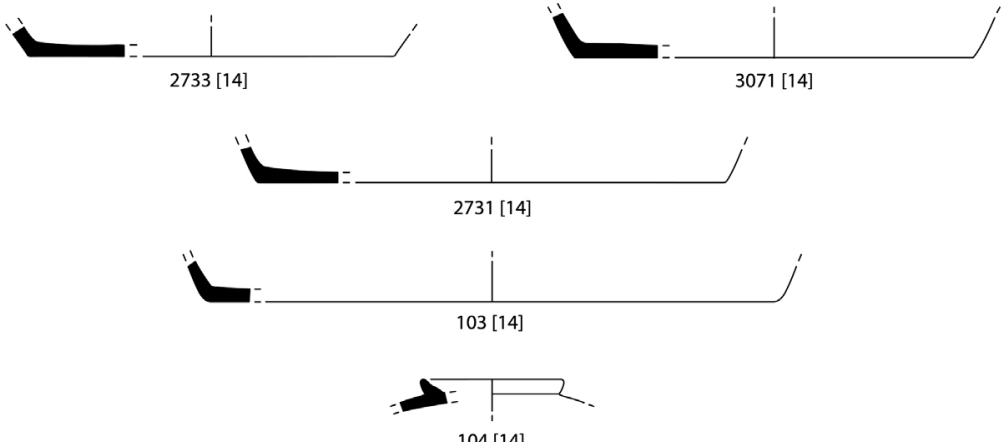

$104[14]$
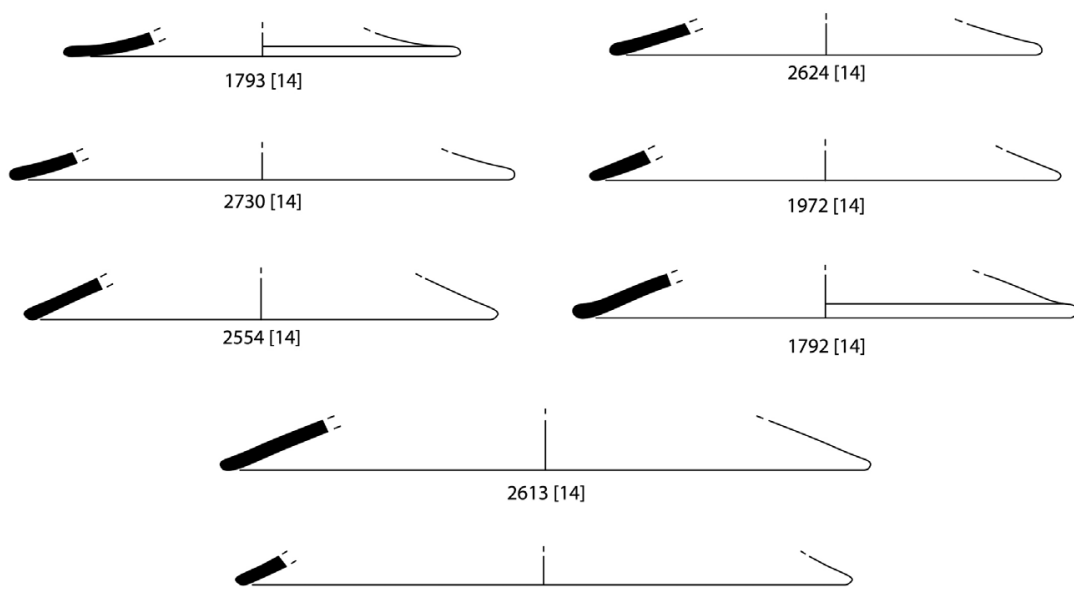

2887 [14]

$10 \mathrm{~cm}$

FIG. 14 - Urbanização do Moleão: tipo COM-IT 6d (395, 2884, 392, 2553, 1966), fundos $(2733,3071,2731,103)$ e tampas $(104,1793,2624,2730,1972$, 2554, 1792, 2613, 2887) de produção itálica. 

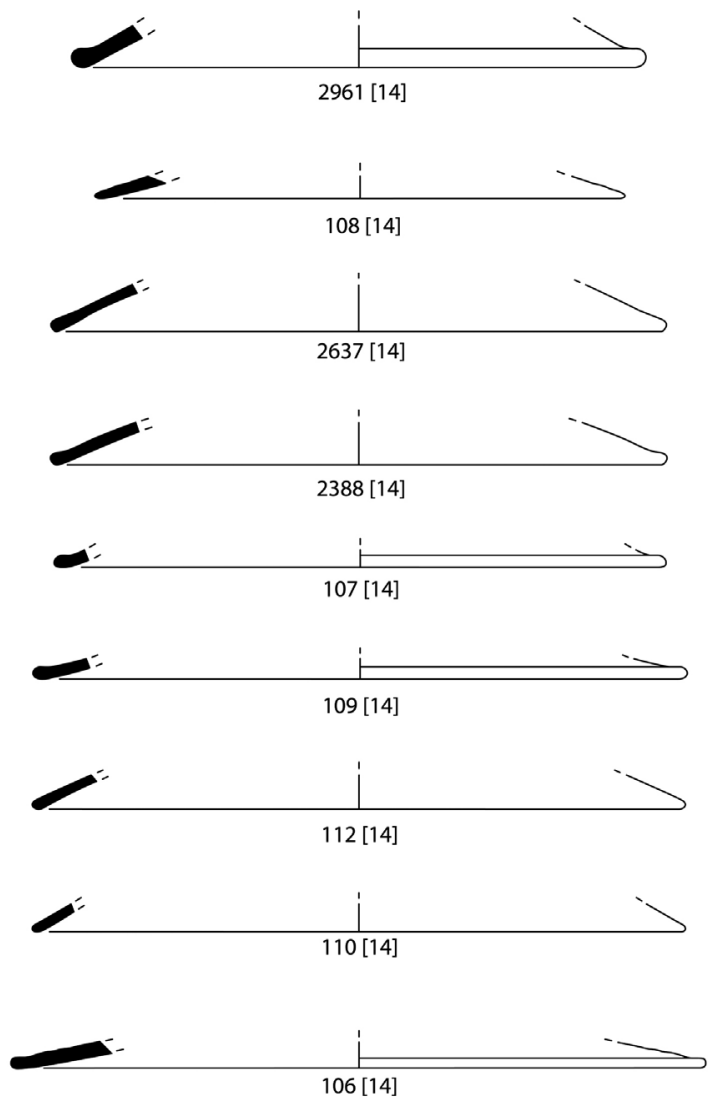

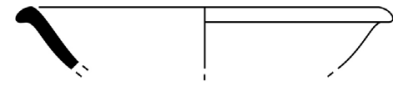

2969 [14]

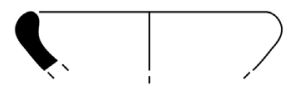

1980 [14]

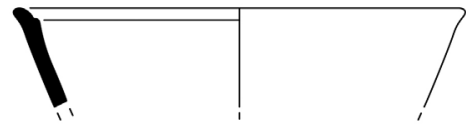

1115 [14]

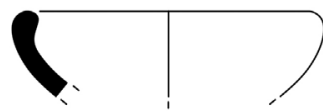

2685 [14] $10 \mathrm{~cm}$

FIG. 15 - Urbanização do Moleão:

tampas (2961, 108, 2637, 2388, 107, 109, 112, 110, 106) de produção itálica; tigelas $(2969,1115)$ e taças $(1980,2685)$ de produção local/regional a torno. 


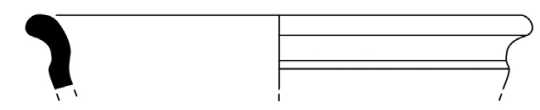

2618 [14]
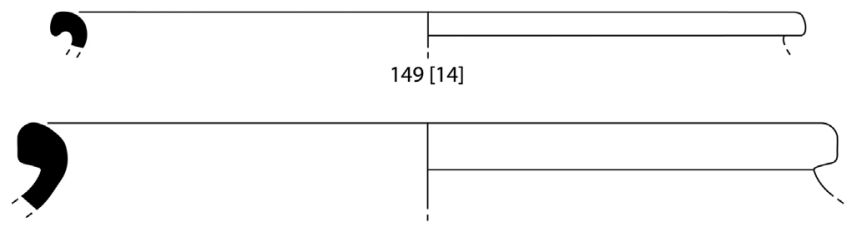

96 [14]

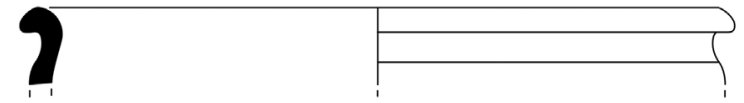

2971 [14]

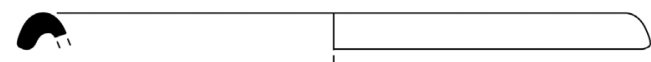

3059 [14]
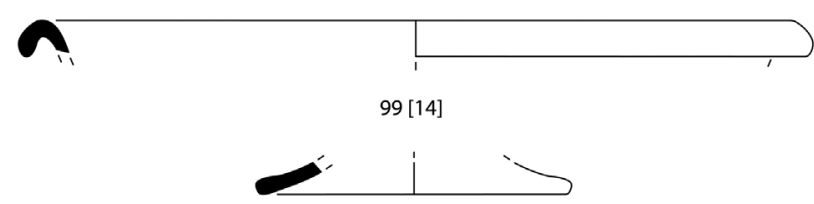

152 [14]

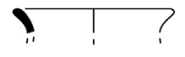

2708 [14]

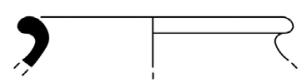

2035 [14]

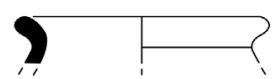

1968 [14]

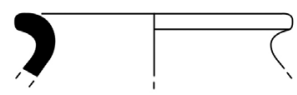

850 [14]

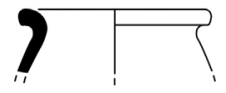

2567 [14]

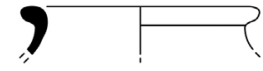

150 [14]

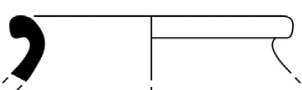

2610 [14]

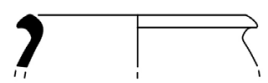

3825 [14]

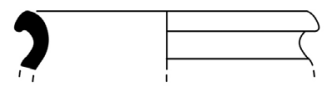

2898 [14]

FIG. 16 - Urbanização do Moleão: alguidares (2618, 149, 96, 2971, 3059, 99), tampa (152) e potes/panelas $(2708,2567,150,2035,2610,1968,3825,850,2898)$ de produção local/regional a torno. 


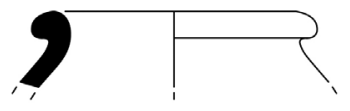

$1953[14]$

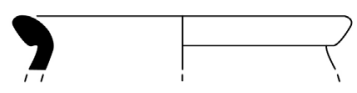

$3072[14]$

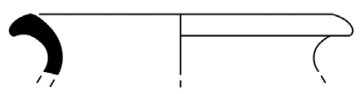

$2824[14]$

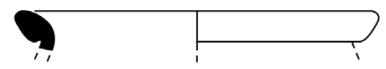

$2323[14]$

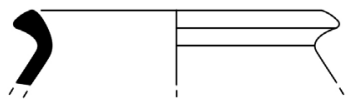

$2301[14]$

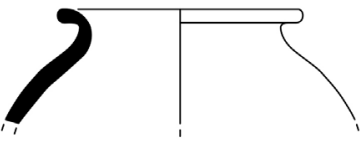

$2329[14]$

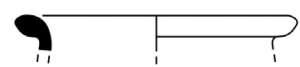

2739 [14]

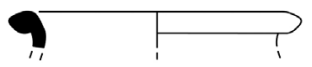

151 [14]

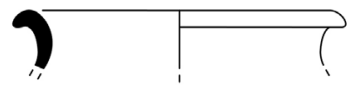

97 [14]

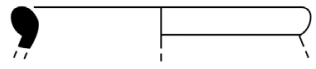

98 [14]

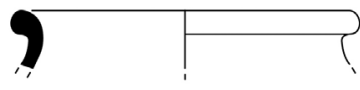

2988 [14]

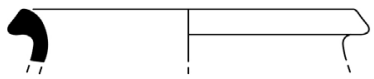

2632 [14]

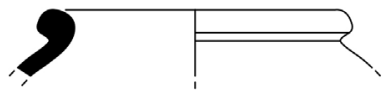

1958 [14]

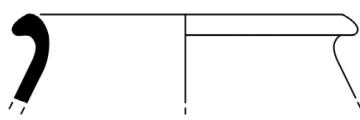

2307 [14]

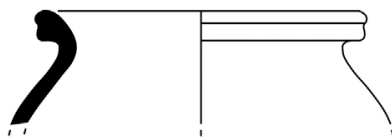

$2978[14]$

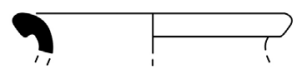

2331 [14]

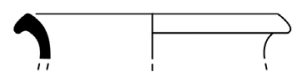

2295 [14]
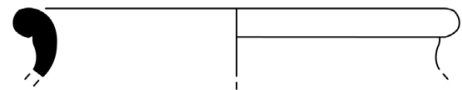

95 [14] $10 \mathrm{~cm}$

FIG. 17 - Urbanização do Moleão: potes/panelas de produção local/regional a torno. 


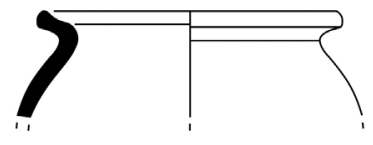

3069 [14]

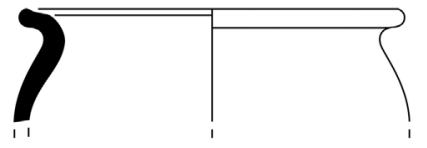

3057 [14]

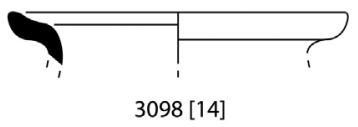

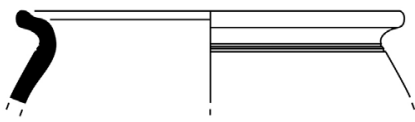

$1651[14]$

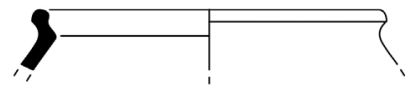

979 [14]

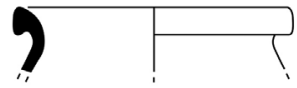

2987 [14]

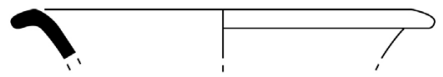

100 [14]

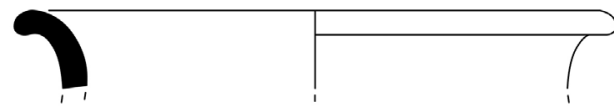

$2296[14]$

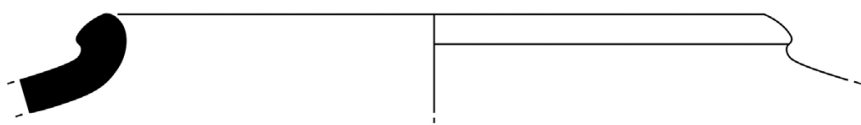

$2037[14]$

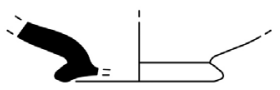

197 [14]

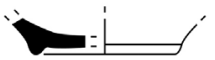

2569 [14]

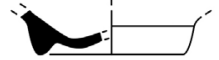

$2729[14]$

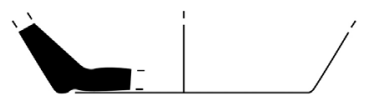

2974 [14]

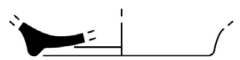

$198[14]$ $10 \mathrm{~cm}$

FIG. 18 - Urbanização do Moleão: potes/panelas (3069, 1651, $3057,979,3098,2987,100)$, grandes recipientes $(2296,2037)$ e fundos $(197,2974,2569,2729,198)$ de produção local/regional a torno. 


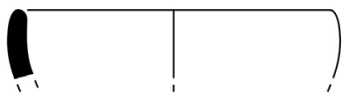

1154 [14]

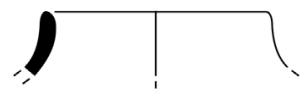

1710 [14]

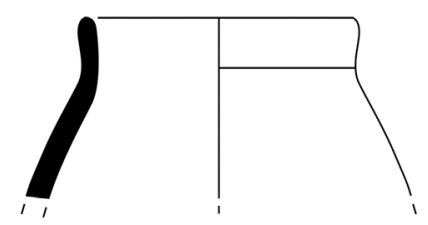

$856[14]$
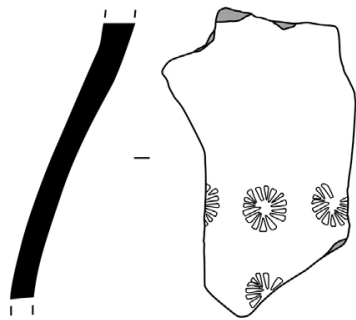

$2361[14]$
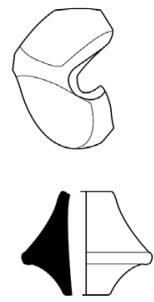

$3852[14]$

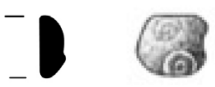

$1713[14]$

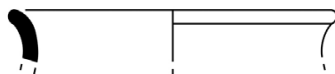

$1650[14]$

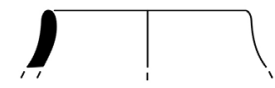

$2303[14]$

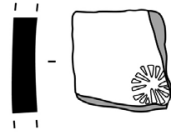

2702 [14]

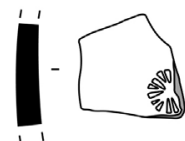

$2362[14]$
$10 \mathrm{~cm}$

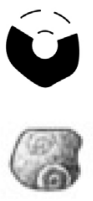

a- (0)

$3317[14]$ $5 \mathrm{~cm}$

FIG. 19 - Urbanização do Moleão: taça (1154),

potes/panelas $(1650,1710,2303,856)$ e fragmentos decorados $(2361,2702,2362)$ de produção manual; contas de colar de pasta vítrea (3852, 1713, 3317). 

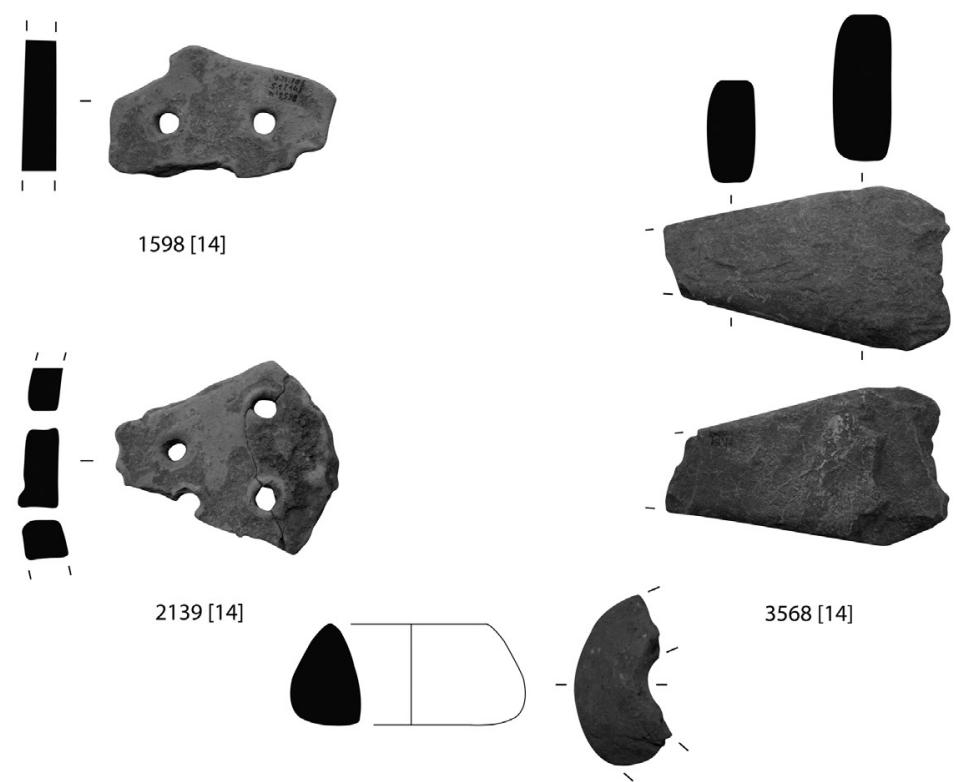

3568 [14]

153 [14]

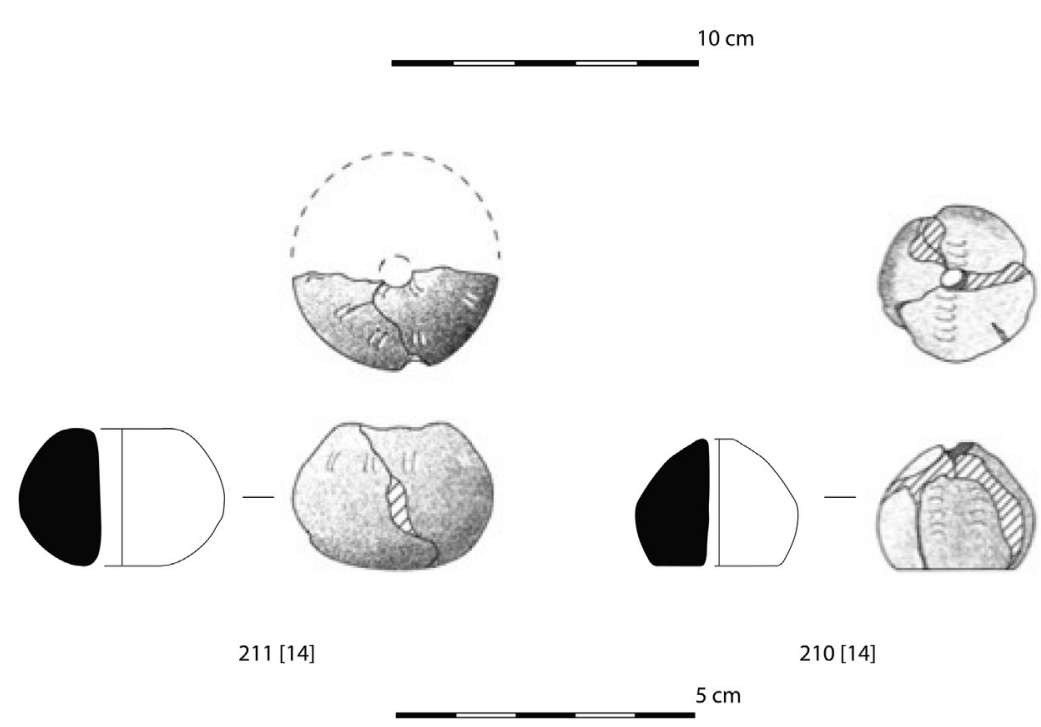

FIG. 20 - Urbanização do Moleão: placas perfuradas (1598, 2139), peso de tear (153), possível pedra de toque (3568) e cossoiros (211, 210). 


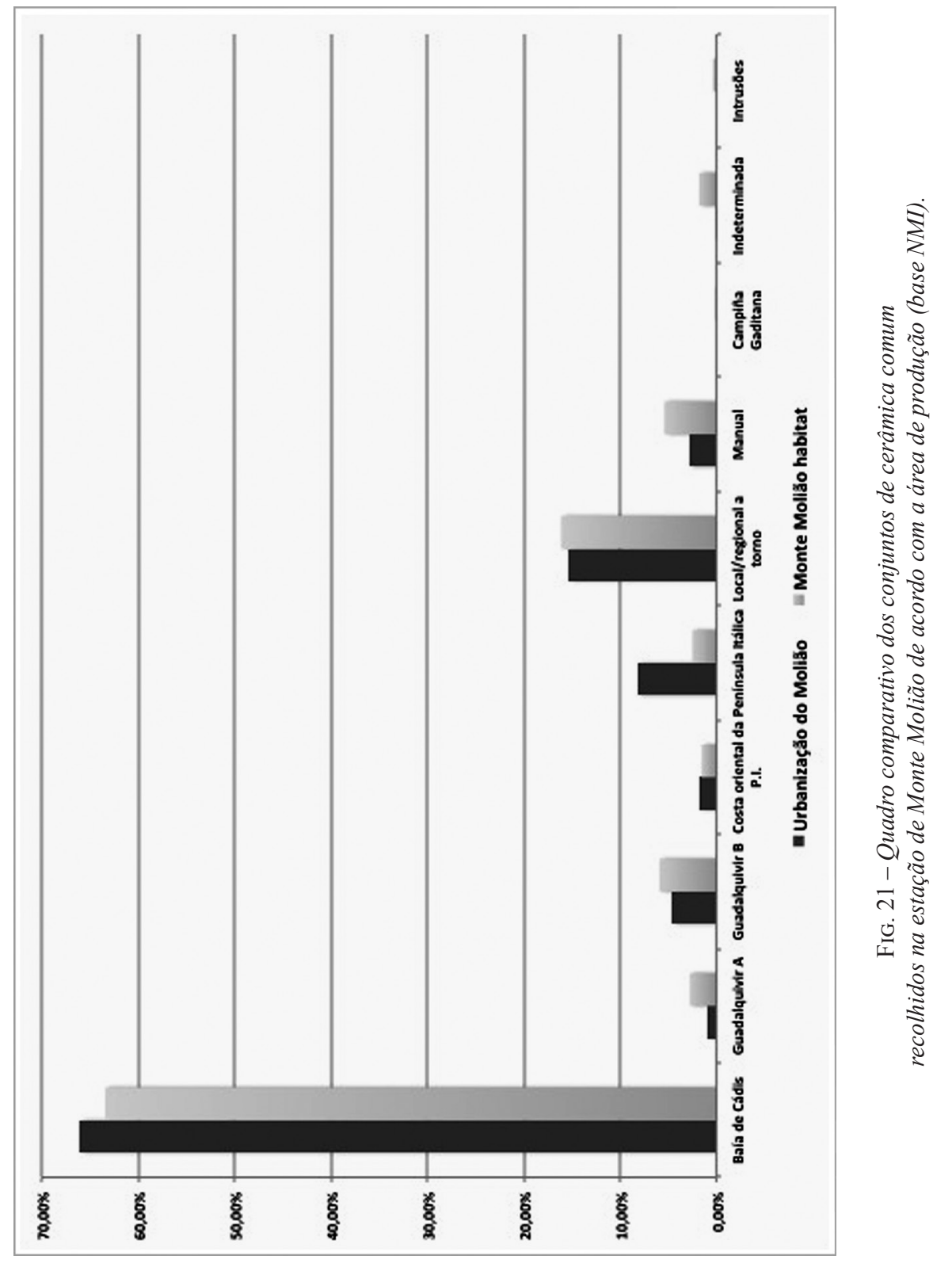




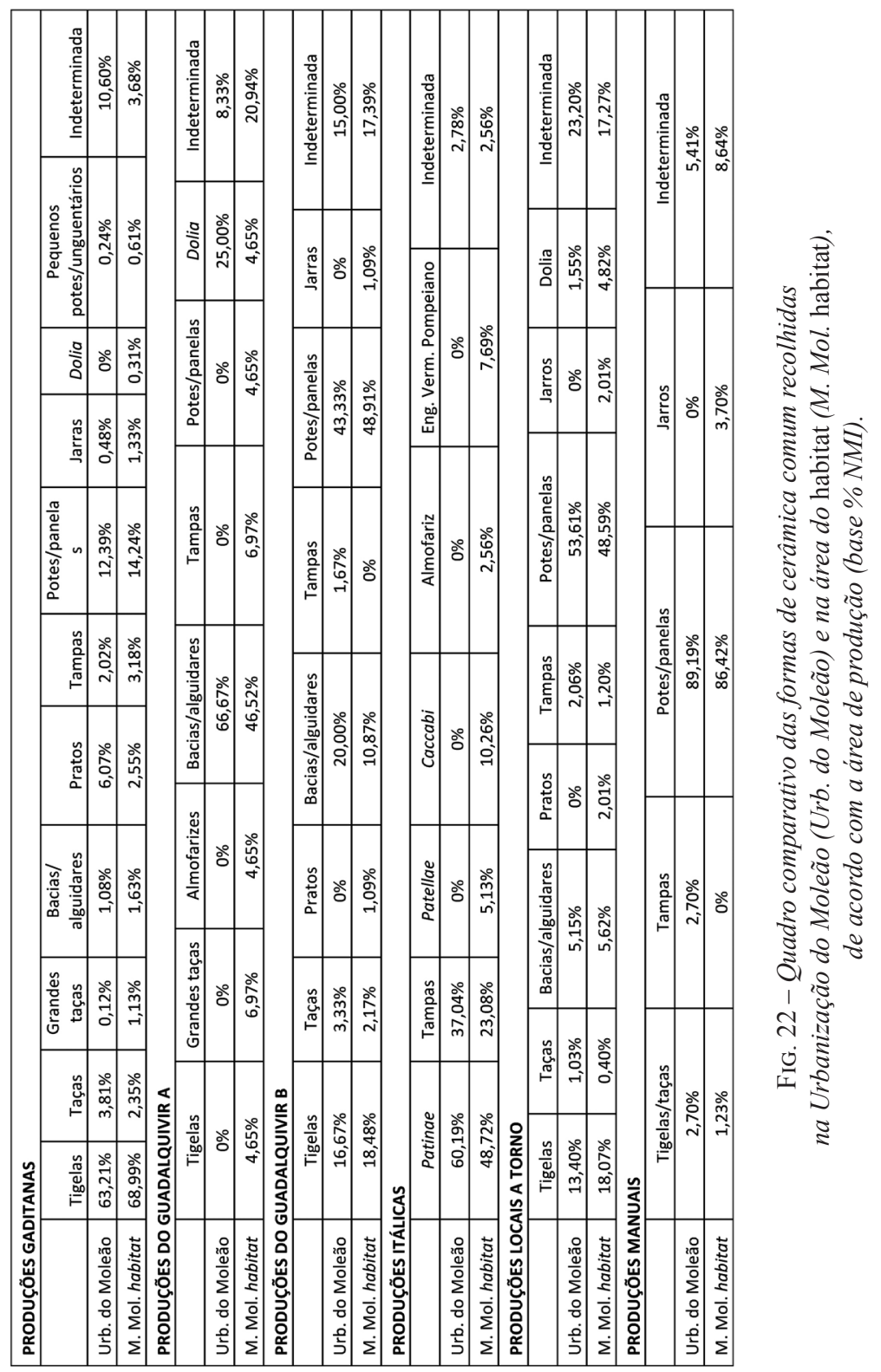

